\title{
Moulded pulp products manufacturing with thermoforming
}

\author{
Didone, Mattia; Tosello, Guido
}

Published in:

Packaging Technology and Science

Link to article, DOI:

10.1002/pts.2412

Publication date:

2019

Document Version

Peer reviewed version

Link back to DTU Orbit

Citation (APA):

Didone, M., \& Tosello, G. (2019). Moulded pulp products manufacturing with thermoforming. Packaging Technology and Science, 32(1), 7-22. https://doi.org/10.1002/pts.2412

\section{General rights}

Copyright and moral rights for the publications made accessible in the public portal are retained by the authors and/or other copyright owners and it is a condition of accessing publications that users recognise and abide by the legal requirements associated with these rights.

- Users may download and print one copy of any publication from the public portal for the purpose of private study or research.

- You may not further distribute the material or use it for any profit-making activity or commercial gain

- You may freely distribute the URL identifying the publication in the public portal

If you believe that this document breaches copyright please contact us providing details, and we will remove access to the work immediately and investigate your claim 


\title{
Molded pulp products manufacturing with thermoforming
}

\author{
Mattia Didone, Guido Tosello \\ Technical University of Denmark, Department of Mechanical Engineering, 2800 Kgs. Lyngby, Denmark
}

\section{Abstract}

Over the past years, eco-friendly packaging solutions such as molded pulp has resonated with a growing number of consumers. Among all of them, the thermoformed products make use of the most recent manufacturing approach that produces high quality, thin-walled items. However, it remains an under-researched area, and the development of an efficient and precise manufacturing process is fundamental in order to increase the implementation of sustainable packaging.

With the purpose of setting a step towards in the standardization of design and testing practices of eco-friendly packaging, this work focused on the characterization of the thermoforming process of molded pulp products and their characteristics. Three different analysis were carried out for this purpose, covering the dewatering efficiency of the process, a quantification of the molding geometrical accuracy and an analysis of the internal microstructure of the parts. Experimental results and statistical analysis show that the dewatering efficiency is mainly governed by the mold's temperature while the duration of the contact time is not influential. In the second investigation, the geometrical accuracy of the moldability of micro-features was assessed. The process appeared to be dependently related to the pulp type employed. Finally, the internal microstructure was documented using computed tomography. The analysis shows an increase in the internal void fraction linked with an increase in the mold's temperature.

The role of the water change of phase in the thermoforming process was also discussed by reference to the work conducted on impulse drying.

Keywords: Molded pulp, molded fiber, thermoforming, impulse drying, 3D structure of paper.

\section{Introduction}

In recent years, economic, environmental and social concerns have resulted in an increasing demand for sustainable packaging products ${ }^{1}$.

Molded pulp is an environmentally friendly packaging material that is recyclable, compostable and eventually biodegradable, and could be used as an alternative to oilbased packaging products such as EPS (expanded polystyrene) or vacuum formed PET (polyethylene terephthalate). In fact, molded pulp consists mainly of water and wood fibers, which are primarily composed of cellulose. 
Molded pulp versatility is remarkable, but its diffusion depends also on the development of an efficient, accurate and robust manufacturing process. The most advanced manufacturing approach in this category is thermoforming ${ }^{1}$. In this process, the initial partially formed product is pressed in a heated mold for a period in the order of tens or hundreds of seconds, where it is densified and dried. The resulting items have good dimensional accuracy and smooth surfaces that resemble the ones of plastic products. Nevertheless, the thermoforming of molded pulp is an energy intensive operation, and a research effort is needed in this direction for making the process more sustainable. Just as in the conventional papermaking industry, a large portion of resources is consumed during the drying process.

Very few reports of recent innovations within the field can be found in the literature ${ }^{2-}$ ${ }^{4}$, and none of them addresses specifically the thermoforming technology. On the other hand, a commonly known technology in the pulp and paper industry that is similar to it in nature is impulse drying, introduced by Wahren ${ }^{5}$ in the 1980s. Impulse drying is an advance drying technique in which water is removed from a wet paper web by the combination of mechanical pressure and intense heat. In this process, the paper web is subjected to a temperature between $100{ }^{\circ} \mathrm{C}$ and $400{ }^{\circ} \mathrm{C}$, and simultaneously pressed at $1.5 \mathrm{MPa}$ to $8 \mathrm{MPa}{ }^{6}$. The dwell, or nip, residence time (i.e. the time in which the paper web is subjected to the combine effect of heat and pressure) is around $20 \mathrm{~ms}$ to $50 \mathrm{~ms}$. This time frame is a consequence of the design of a conventional press nip for the papermaking industry, which is a continuous flow process.

Impulse drying technology proved to offer enhanced dewatering and physical properties of paper sheets 7,8 . Its mechanism is complex and the physics underlying the phenomenon was never fully described. It was suggested that if the heat transfer rate is sufficiently high, a high-pressure steam is generated on the surface of the paper web next to the hot medium. The steam expansion could then aid in the displacement/removal of the water held between the fibers ${ }^{5,9,10}$. This effect was most recently studied and termed "flashing-assisted displacement dewatering" by Lucisano et al. ${ }^{11}$. In their research, it was experimentally proved that the displacement of liquid water by the action of an expanding steam layer plays a significant role in the physics of dewatering during an impulse drying event.

An undesired and secondary phenomenon that is also linked to the expanding steam is called delamination 6,7 . It is mainly caused by an imbalance between the pressure within the sheet and the external, atmospheric, pressure ${ }^{12}$. When the drag forces resulting from the escaping vapor overcome the cohesive forces holding the paper web together, the sheet delaminates ${ }^{13}$.

From the perspective of the products characteristics and quality assurance, the geometrical accuracy of the parts and their internal structure are two important aspects.

In a molding process, when evaluating the capability of molding features at the microscale, the accuracy of the replicated features with respect to the master geometry has to be quantified ${ }^{14}$. For this purpose, various dimensional measurement solutions can be applied ${ }^{15}$. Among all of them, optical instruments are strongly emerging because of their distinctive advantages ${ }^{16}$. Their contact-less and non-destructive nature makes them suitable for measuring soft components: in fact, even a small force would invalidate the measurement by damaging the molded pulp surface. They are also 
typically faster than contact instruments such as coordinate-measuring machines and profilometers ${ }^{17}$.

The internal structure of molded pulp products determines instead transport properties such as permeability to water and moisture, electrical and thermal conductivity. It is thus of importance for assessing the packaging durability and whether there is the need for selecting an appropriate coating to be combined with the molded pulp item. Computed tomography (CT) is an established technique for acquiring 3D images that can be used to characterize the internal structure of a wide variety of materials, including paper.

At the pore scale, a fundamental structural unit can be assumed to repeat itself. This fundamental repeating unit has often been referred to as representative elementary volume (REV), and by assessing the properties of various REV geometries, it is possible to scale the transport properties of the entire porous media ${ }^{18,19}$. The pore structure of paper is complex and presents significant interconnectivity, as exemplified by the reconstruction of paper using synchrotron beam radiations CT reported in $20-25$. Despite the advantages in terms of resolution of acquisition of synchrotron CT, conventional CT setup is widely used and constantly improved. It was in fact used among others by Wernersson et al. ${ }^{26}$, Sharma et al. ${ }^{27}$ and Miettinen et al. ${ }^{28}$.

With the purpose of setting a step towards in the standardization of design and testing practices of eco-friendly packaging, this work focused on the characterization of the thermoforming process of molded pulp products and their characteristics. In particular, this work comprises of three investigations. The first one aims at characterizing the process while the other two focus on the geometrical accuracy and internal structure of the parts.

In the first investigation, the dewatering efficiency of a thermoforming process was quantified and the influence of the process parameters discussed. Inspired by the findings around the impulse drying technology, the molded pulp samples of this work were thermoformed at temperatures above the normal boiling point of water (around $100{ }^{\circ} \mathrm{C}$ ) and at a pressure of $1.9 \mathrm{MPa}$ and $2.5 \mathrm{MPa}$. Although these conditions resemble the ones of the impulse technology, and because of the different tooling design of a molded pulp machine, the samples were dried for periods in the order of seconds. Consequently, the technology employed in this work is not addressed as impulse. The goal of the first study was to gain a better understating of the thermoforming process for making it optimized and more sustainable.

The second investigation focused on the capability of molding features at the microscale. Different type of geometrical micro-features were molded on the surface of the thermoformed molded pulp samples. A laser-scanning confocal digital microscope was thus employed for measuring the geometry of the master and of the replicated features. The two measurements were compared and a quality indicator was defined.

In the third analysis, CT inspections were carried out using a conventional setup in order to evaluate the voids or pores distributions within a specified REV of selected thermoformed molded pulp samples.

For clarity for the reader, each chapter is subdivided into the three experimental works, namely: 
- Effect of the process parameters on the dewatering efficiency.

- Replication quality of micro-features.

- Void analysis with computed tomography.

An overall discussion on the results of the three analysis is given in the conclusive chapters.

The experiments described in this work represent a first step in understanding the thermoforming process of molded pulp products manufacture. The experiments are limited to one type of fiber and to a relatively flat products geometry. The main purpose is in fact to present methods and techniques that can be employed for improving on the technology level of molded pulp production. This topic have received scarce attention in the literature and no direct investigations are available. The aim of this study is to contribute in filling this gap and to consolidate best practices in order to increase the diffusion of environmentally friendly packaging products.

\section{Methods}

Figure 1 shows the scheme of the laboratory-scale thermoforming machine employed throughout this work. The machine thermoforms pre-formed molded pulp disks with a diameter of $100 \mathrm{~mm}$ (Figure 2). The paper disks were formed with a custom-made sheet former that resembles the TAPPI T 205 test method ${ }^{29}$. The disk were formed with an initial dryness level around $25 \%$, and a basis weight of $600 \mathrm{~g} / \mathrm{m}^{2}$. The samples were made of commercially available bleached chemical pulp. The pre-formed disks had a thickness around $10 \mathrm{~mm}$, which reduced to half after being thermoformed.

The system consists of a double acting cylinder that presses two halves of a mold together. The upper half of the mold is fixed to the outer frame and is heated via two cartridge heaters. The bottom half of the mold is moved upwards by the double acting cylinder and the upward movement stops when the imposed level of pressure is reached. The pre-formed paper disks are placed in the bottom half of the mold on top of a fine metal wire mesh. The mesh covers a series of holes that allows for the removing of the water/steam via vacuum suction during the process.

The laboratory-scale machine was operated as follows:

i) The upper half of the mold was heated to the imposed level of temperature.

ii) A wet pre-formed paper disk was positioned in the bottom half of the mold and this was moved upwards by the double-acting cylinder until the imposed level of mechanical pressure was reached.

iii) The mechanical pressure and the temperature were kept constant for a defined time, named contact time.

iv) After the contact time was elapsed, vacuum suction was applied for a defined time, named vacuum time.

v) The mechanical pressure was released; the molded disk was collected and weighted for assessing the dryness level.

Highlighted in bold are the process parameters object of the first experimental investigation: temperature, pressure, contact time and vacuum time. 


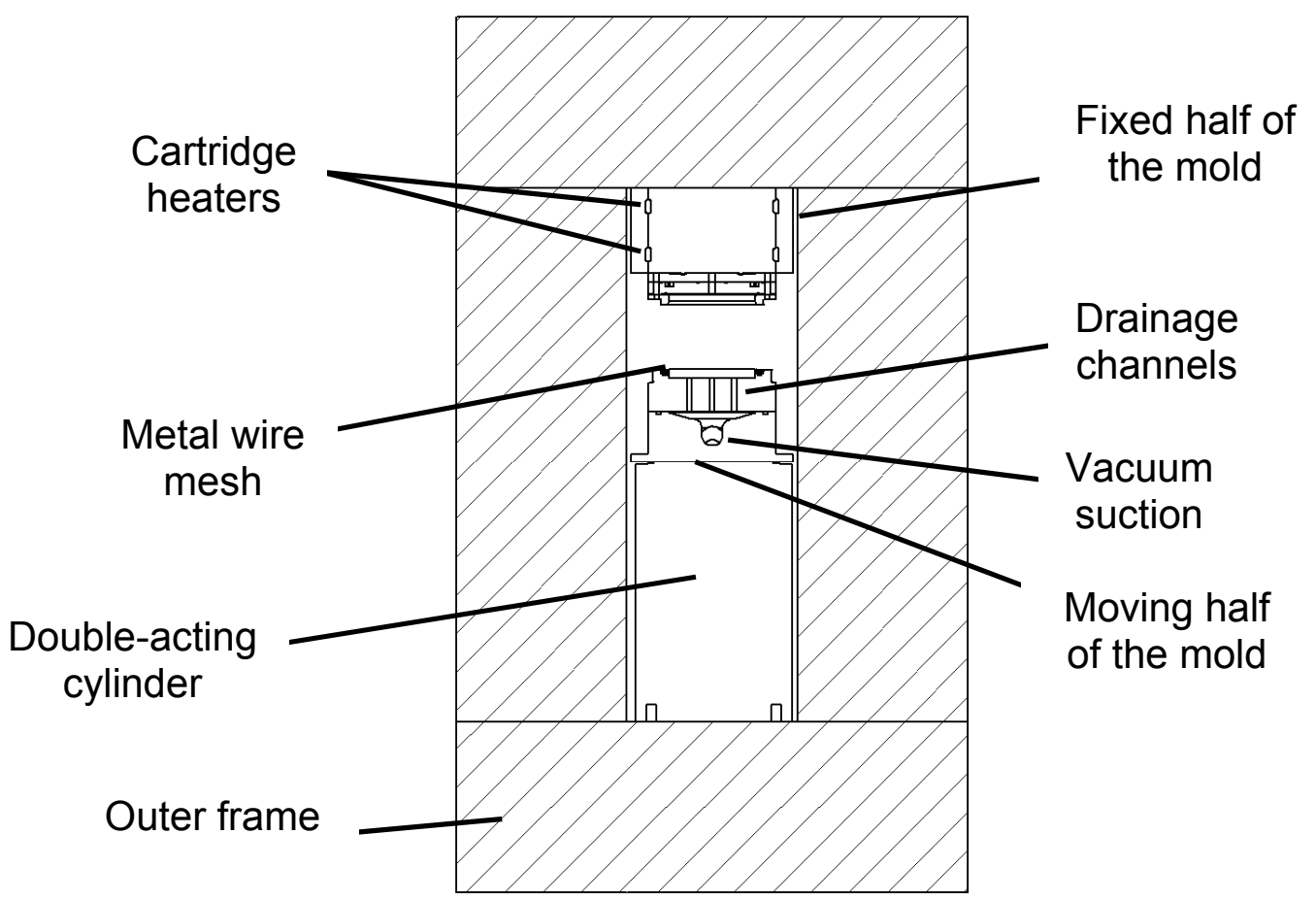

Figure 1: Scheme of the laboratory-scale thermoforming machine.

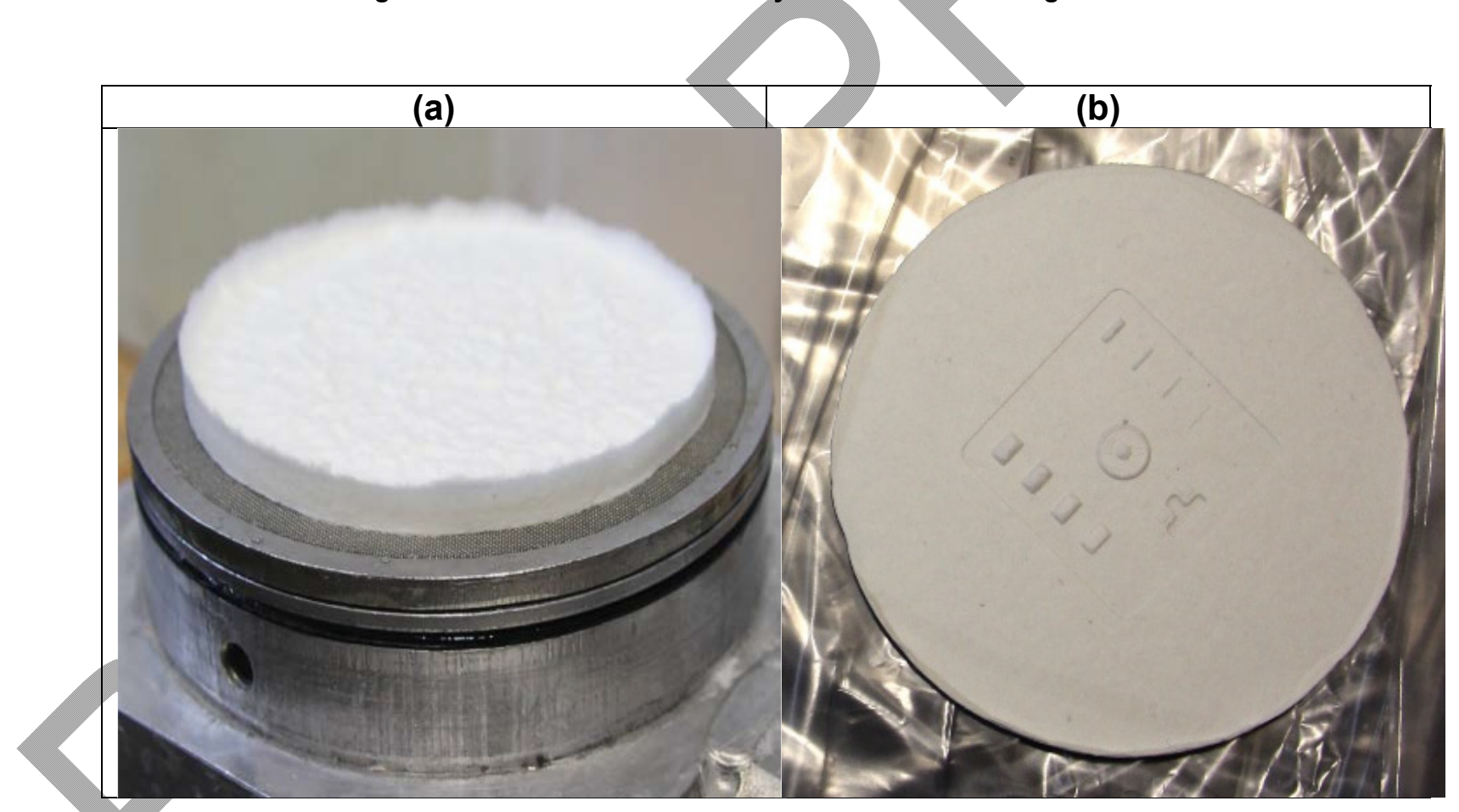

Figure 2: (a) Pre-formed wet paper disk. Initial thickness around $10 \mathrm{~mm}$. (b) Thermoformed molded paper pulp disks. Final thickness around $5 \mathrm{~mm}$. Diameter (before and after the thermoformed event) equals to $100 \mathrm{~mm}$.

\section{Effect of the process parameters on the dewatering efficiency}

The dewatering efficiency was assessed by measuring the weight of the molded disks after the drying event and after they were bone-dried; the dryness level was consequently calculated according to equation (1). 


$$
\text { Dryness }=\frac{\text { bone dry mass }(g)}{\text { total mass }(g)} \%
$$

Where bone dry mass is the mass of the dry fibers.

total mass is the mass of the thermoformed disk that consists of the residual water and fibers.

A statistically designed experiment was carried out in order to investigate the influence of the process parameters with respect to the dryness level. Four different parameters were varied in order to determine their influence on the thermoforming process, according to Table 1. A full factorial 4-factors 2-levels design of experiment (DOE) was created. Each experimental setup was replicated three times, for a total of 48 experiments.

Table 1: Process parameters settings and full-factorial 4-factors 2-levels design of experiments (DOE) for the dewatering efficiency investigation.

\begin{tabular}{|c|c|c|c|c|c|c|c|c|c|c|c|c|c|c|c|c|c|c|c|}
\hline Parameter & Unit & Low level & High level & \multicolumn{10}{|c|}{ Design of experiments setups } \\
\hline & & - & $\mathbf{+}$ & $\mathbf{1}$ & $\mathbf{2}$ & $\mathbf{3}$ & $\mathbf{4}$ & $\mathbf{5}$ & $\mathbf{6}$ & $\mathbf{7}$ & $\mathbf{8}$ & $\mathbf{9}$ & $\mathbf{1 0}$ & $\mathbf{1 1}$ & $\mathbf{1 2}$ & $\mathbf{1 3}$ & $\mathbf{1 4}$ & $\mathbf{1 5}$ & $\mathbf{1 6}$ \\
\hline Contact time & $\mathrm{s}$ & 2 & 6 & + & - & + & - & + & - & + & - & + & - & + & - & + & - & + & - \\
\hline Vacuum time & $\mathrm{s}$ & 2 & 6 & + & + & - & - & + & + & - & - & + & + & - & - & + & + & - & - \\
\hline Temperature & ${ }^{\circ} \mathrm{C}$ & 100 & 200 & + & + & + & + & - & - & - & - & + & + & + & + & - & - & - & - \\
\hline Structural pressure & $\mathrm{MPa}$ & 1.9 & 2.5 & + & + & + & + & + & + & + & + & - & - & - & - & - & - & - & - \\
\hline
\end{tabular}

During the thermo-compression, the boiling of the majority of the water content inside the sample is prevented by the application of the structural pressure. In the experiments performed in this work, the lowest value of structural pressure employed was of $1.9 \mathrm{MPa}$, to which corresponds a water boiling point of $209^{\circ} \mathrm{C}$.

Regarding the role of the temperature, during a thermoforming process, the heat is mainly transferred via conduction from the heated mold in direct contact with the sample.

A model presented by Palosaari in $1976{ }^{30}$ successfully describes heat transport in a wet capillary-porous materials, coupling the different heat transfer mechanisms as if they were partly in series and partly in parallel. A simplified version of the model was simulated to obtain an estimate of the process parameter named contact time. The effective thermal conductivity $\left(\lambda_{e f f}\right)$ of the molded pulp was modelled according to the equations in (2). The Fourier's heat conduction equation was then solved using the Crank-Nicolson method in a one-dimensional domain, i.e. along the thickness direction of the sample. Figure 3 depicts the enmeshment of the domain that represented the thickness of the pre-formed molded pulp sample $(10 \mathrm{~mm})$. Fixed boundary conditions were chosen for the extremes of the domain, i.e. equal to the upper-mold temperature on one side and to the bottom-mold temperature on the other. 


$$
\begin{gathered}
\lambda_{p a r}(T, p)=\lambda_{s} \varepsilon_{s}+\lambda_{w}(T, p) \varepsilon_{w} \\
\frac{1}{\lambda_{s e r}(T, p)}=\frac{1}{\frac{\varepsilon_{s}}{\lambda_{s}}+\frac{\varepsilon_{w}}{\lambda_{w}(T, p)}} \\
\lambda_{e f f}(T, p)=\frac{1}{\frac{1-a}{\lambda_{s e r}}+\frac{a}{\lambda_{p a r}}}
\end{gathered}
$$

Where

$\lambda_{\text {par }}(T, p)$ is the parallel thermal conductivity.

$\lambda_{s}$ is the solid thermal conductivity, set equal to $0.157 \mathrm{~W} /(\mathrm{mK})$ 31 .

$\varepsilon_{s}$ is the solid volume fraction, considered equal to 0.25 (i.e. the initial disk dryness level).

$\lambda_{w}(T, p)$ is the water thermal conductivity, as a function of operational temperature and pressure.

$\varepsilon_{w}$ is the water volume fraction, complementary of $\varepsilon_{s}$.

$\lambda_{s e r}(T, p)$ is the series thermal conductivity.

$a$ is an empirical parameter chose equal to $0.46^{30}$.

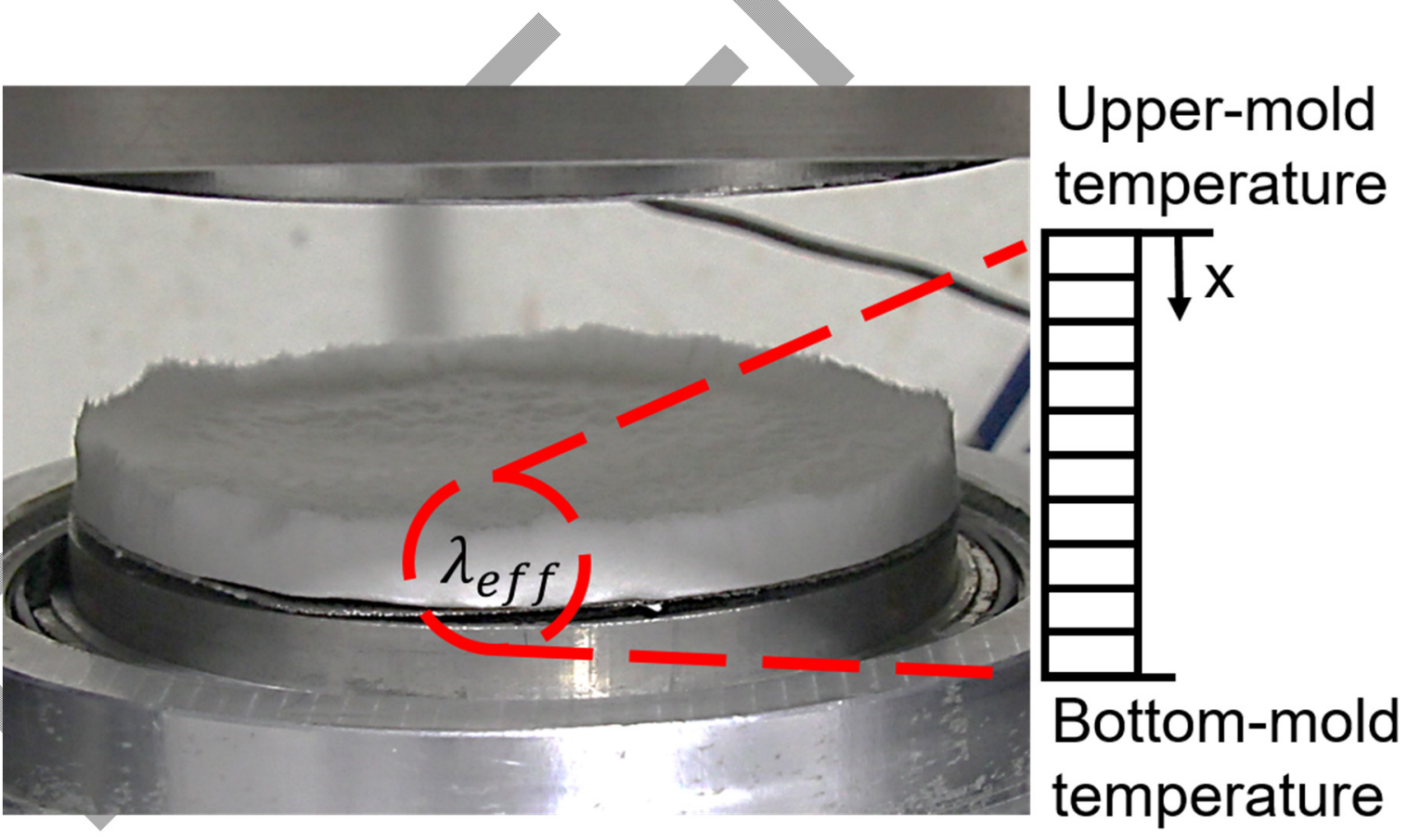

Figure 3: One-dimensional enmeshment of the pre-formed molded pulp sample. Mesh used to simulate the heat conductivity, solved for the temperature.

According to the simulation, after a contact time of $2 \mathrm{~s}$ a temperature of $86^{\circ} \mathrm{C}$ was reached within the paper disk, and after $6 \mathrm{~s}$ a temperature of $137^{\circ} \mathrm{C}$ (Figure 4). 
In this simulation, it was not taken into account the effect of the pulp compression (i.e. volume reduction) that certainly helps the heat to diffuse. In any case, the time of heat conduction through the wet paper pulp is due to the thermal resistivity of the whole media, which supposedly increases as water is removed.

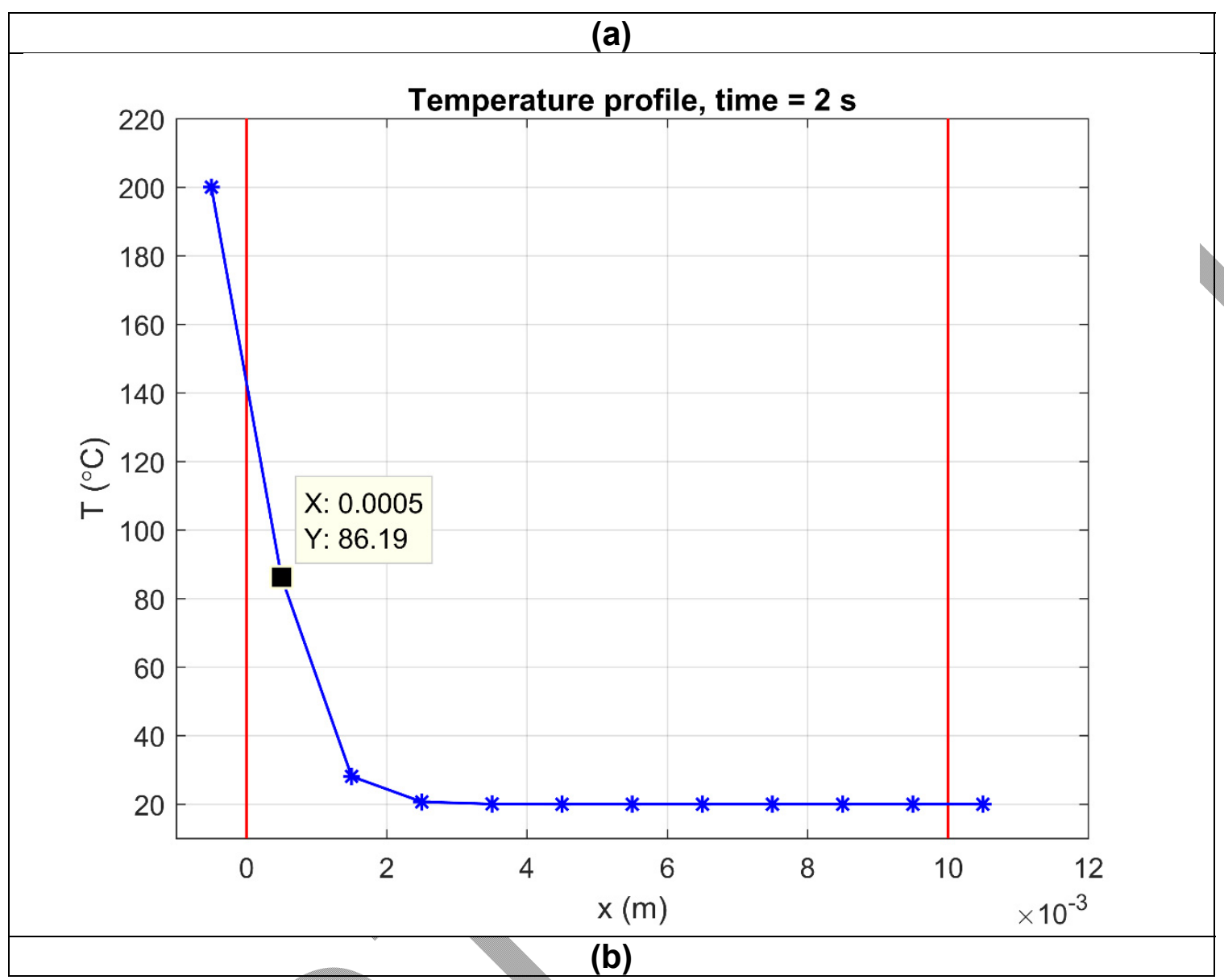




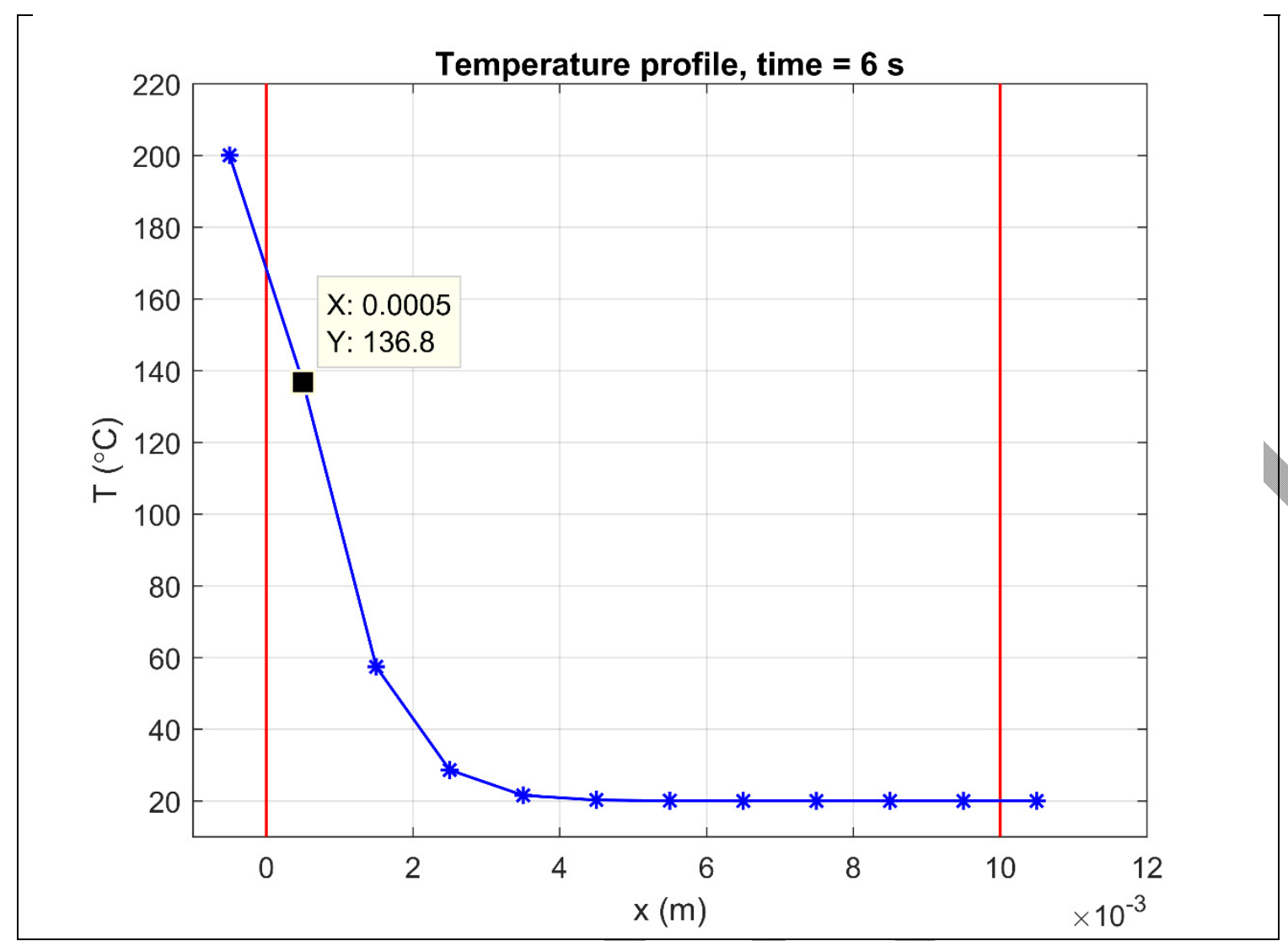

Figure 4: (a) Simulation's result of the heat conduction within the molded pulp sample after a contact time of $2 \mathrm{~s}$, and of $6 \mathrm{~s}(\mathrm{~b})$.

\section{Replication quality of micro-features}

The fidelity of the replication of features at the micro-scale molded on paper was quantified via optical instrumentation by calculating a quality indicator, named deviation. The impact of two process parameters, temperature and cycle time, on the replication quality was also determined.

Figure 5 shows the scheme of an insert that was embedded in the upper half of the mold of the laboratory-scale thermoforming machine. The aluminum insert, with lateral dimension of $40 \mathrm{~mm}$, was coated with PTFE (polytetrafluoroethylene) to avoid the sticking of the paper fibers due to the high temperatures involved. In Figure 5 (a) the dimensions (in $\mathrm{mm}$ ) of the geometrical features are reported. In Figure 5 (b) an image of the actual insert coated with PTFE is depicted. Figure 5 (c) shows the replicated features on the molded pulp sample's surface.

(a) 


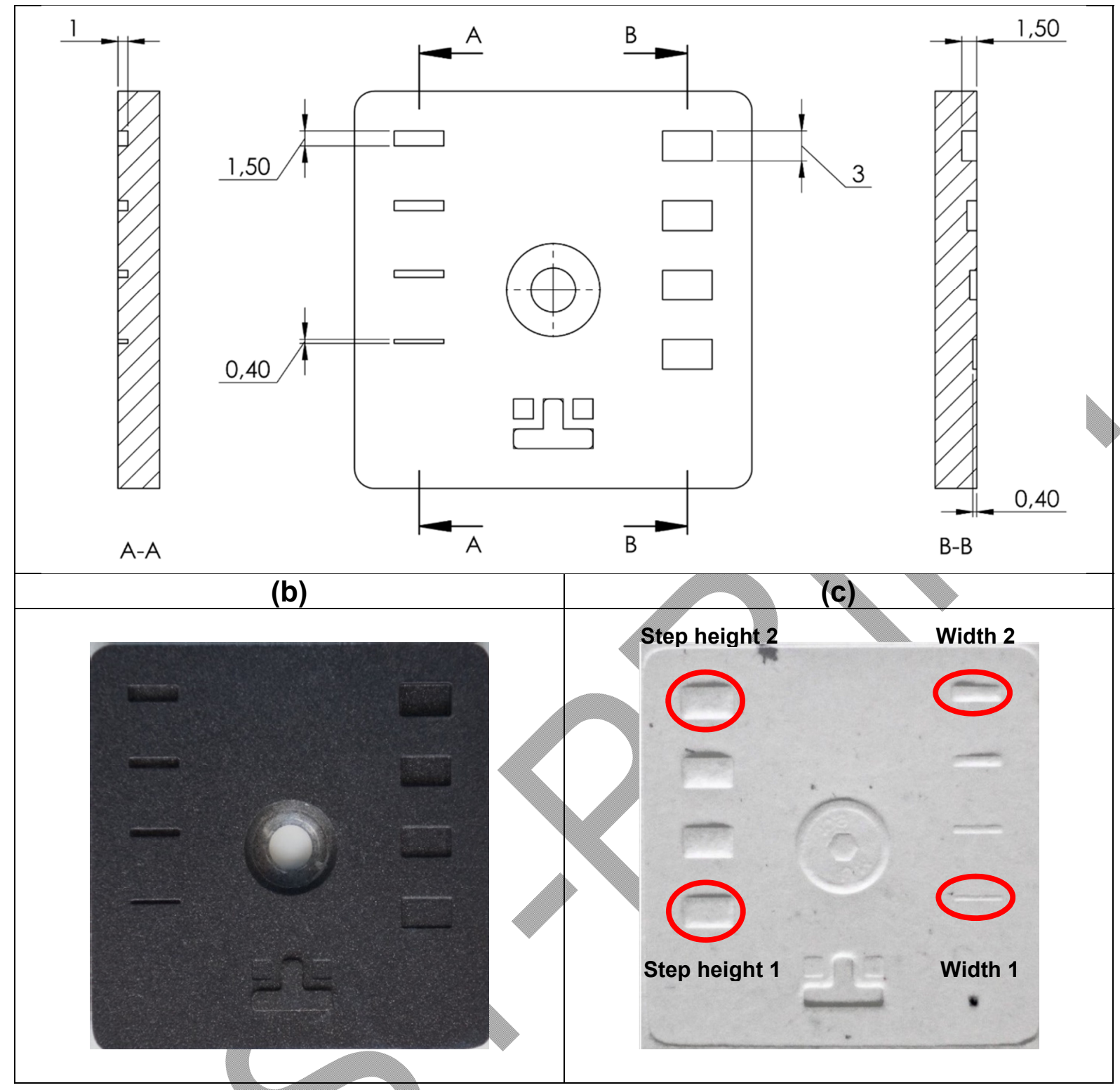

Figure 5: (a) Scheme of the mold insert with the dimensions in $\mathrm{mm}$ of the geometrical features. (b) Image of the mold's insert coated with PTFE. (c) Image of the geometrical features replicated on the molded pulp's surface (circled in red).

The investigation was focused on two geometrical feature types, namely Step height and Width. Four geometries, two of the Step height type and two of the Width type, were machined on the mold's surface with a micro machining system. The nominal dimensions are reported for clarity in Table 2.

Table 2: Nominal dimensions of the geometrical features machined on the mold's surface.

\begin{tabular}{|c|c|c|c|}
\hline Feature type & Unit & Depth & Width \\
\hline Step height 1 & $\mathrm{mm}$ & 0.4 & 3 \\
\hline Step height 2 & $\mathrm{mm}$ & 1.5 & 3 \\
\hline Width 1 & $\mathrm{mm}$ & 1 & 0.4 \\
\hline Width 2 & $\mathrm{mm}$ & 1 & 1.5 \\
\hline
\end{tabular}

A statistically designed experiment was carried out in order to investigate the influence of the temperature and of the cycle time on the moldability of the geometrical features. 
A full factorial 2-factors 2-levels DOE was created (Table 3). Each experimental setup was replicated five times, for a total of 20 experiments. The structural pressure was kept constant at $2.5 \mathrm{MPa}$. The outgoing level of dryness of the samples was above $90 \%$. After the production, the samples were stored in a room with a controlled temperature of $21^{\circ} \mathrm{C}$ and relative humidity $(\mathrm{RH})$ of $50 \%$ for 72 hours for stabilizing the items before measuring them.

Table 3: Process parameters settings and full-factorial 2-factors 2-levels design of experiments (DOE) for the replication quality investigation.

\begin{tabular}{|c|c|c|c|c|c|c|c|}
\hline Parameter & Unit & Low level & High level & \multicolumn{5}{|c|}{ Design of experiments setups } \\
\hline & & - & + & $\mathbf{1}$ & $\mathbf{2}$ & $\mathbf{3}$ & $\mathbf{4}$ \\
\hline Cycle time & S & 8 & 18 & - & + & - & + \\
\hline Temperature & ${ }^{\circ} \mathrm{C}$ & 120 & 160 & - & - & + & + \\
\hline
\end{tabular}

To assess the replication quality, that is to quantify how closely the geometrical features replicated on the molded pulp disks resemble the ones on the mold's (or master) surface, an indicator named deviation was defined. This indicator was calculated according to equation (3). A higher quality of replication is achieved when the indicator is close to zero.

$$
\text { Deviation }=\frac{\text { mold's feature }(\mu m)-\text { replicated feature }(\mu m)}{\text { mold's feature }(\mu m)} \%
$$

The measurements of both the master's and of the replicated features were carried out using a laser-scanning confocal digital microscope (LEXT OLS4100 from Olympus Corporation, Tokyo, Japan). The characteristics of the instrument are reported in Table 4.

Table 4: Olympus LEXT OLS4100 laser scanning digital microscope characteristics.

\begin{tabular}{|c|c|c|}
\hline Parameter & Unit & Value \\
\hline Objective magnification & - & $5 \mathrm{x}$ \\
\hline Numerical aperture & - & 0.15 \\
\hline Working distance & $\mathrm{mm}$ & 20 \\
\hline Field of view & $\mu \mathrm{m}$ & $2560 \times 2560$ \\
\hline
\end{tabular}

With the aim of acquiring the entire extension of the Step height features, a rectangular area of $6.0 \times 2.0 \mathrm{~mm}$ was acquired. In particular, a stitching operation of 3 images was automatically performed. For measuring the Width features, only one image was acquired, given the field the view offered by the instrument (Table 4).

After the measurements, the data sets were processed with a dedicated image metrology software (SPIP тм ${ }^{32}$, Image Metrology A/S, Hørsholm, Denmark). A firstdegree alignment was considered to flattened the images' surfaces and ensure a correction for a potential tilt of the samples. The depth of the Step height features was defined as the vertical distance between two parallel planes that include an elevation and the substrate. It was so calculated via the software based on height distribution histogram, measuring the difference between the two peaks (as shown in Figure 6 (a)). The width was defined as the horizontal distance between two points placed on the two sides of the Width features at the intersection between the average profile and 
the mean height line. Figure 6 (b) depicts the average profile of a Width feature and the method applied for measuring the width via the metrology software.

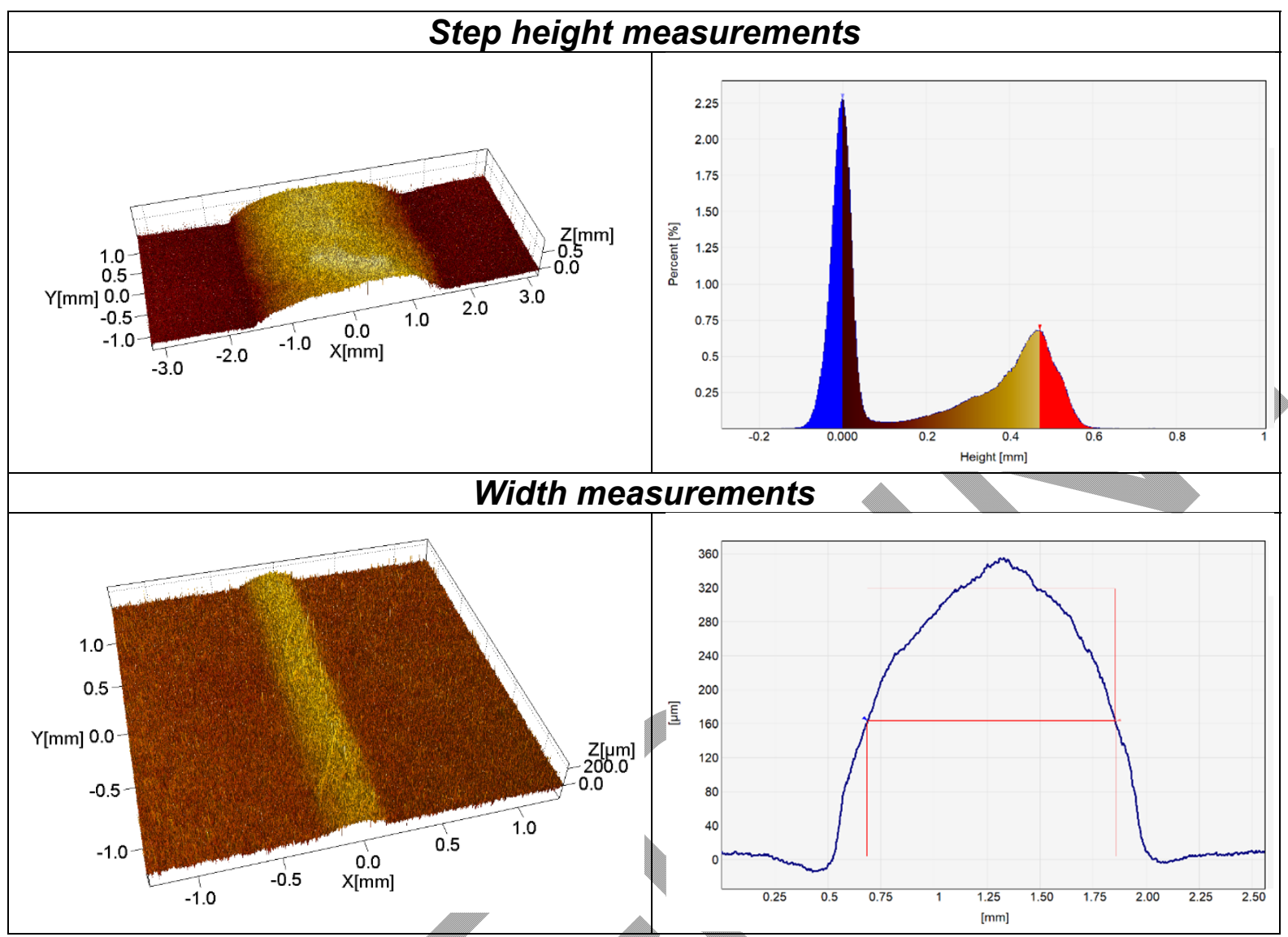

Figure 6: Step height (top) and Width (bottom) measurements via a dedicated metrology software.

\section{Void analysis with computed tomography}

Computed tomography (CT) inspections were carried out in order to evaluate the voids distributions within the molded pulp samples. Furtherly, the relation between the voids size and the number of occurrence with respect to the process parameters was discussed.

The visual inspections carried out using the confocal microscope did not give any information about the internal microstructure of the molded pulp samples. Taking advantage of the capability of X-rays to penetrate a material ${ }^{33,34}$, CT proved to be the suited method for this purpose.

Four samples were selected from the previous study, each of which manufactured with a different setup of process parameters, as shown in Table 5. The molded pulp disks were cut around a selected area to obtain a piece with a small thickness to width ratio.

Table 5: The four samples selected for the CT inspections and the relative process parameters

\begin{tabular}{|c|c|c|}
\hline Sample & Temperature $^{\circ} \mathbf{C}$ & Cycle time, $\mathbf{~}$ \\
\hline 1 & 120 & 8 \\
\hline 2 & 120 & 18 \\
\hline 3 & 160 & 8 \\
\hline 4 & 160 & 18 \\
\hline
\end{tabular}


The obtained samples were glued on the rotating stage of the CT machine, and the area of interested was placed in the center of the support, as shown in Figure 7 (a) and Figure 7 (b).

Once the samples were placed in the CT hutch, the CT was stabilized for $1 \mathrm{~h}$; otherwise, thermal drifts would had impaired the measurements. Being the samples made of paper, a stable environment in terms of temperature and humidity was of extreme importance.

The four samples were scanned using a Nikon XT H 225 industrial CT (Nikon, Tokyo, Japan). Table 6 shows an overview of the scanning parameters used in this work. The beam absorption of paper is known to be very weak, and thus usually low voltage is applied $21,23,27,35$. On the contrary, the current determines the contrast of the workpiece, and its value was set relatively high, i.e. $2 \mathrm{~A}$. The target was selected to suit the low voltage X-ray source, and the popular material for this purpose is molybdenum, as reported in 28,36 .

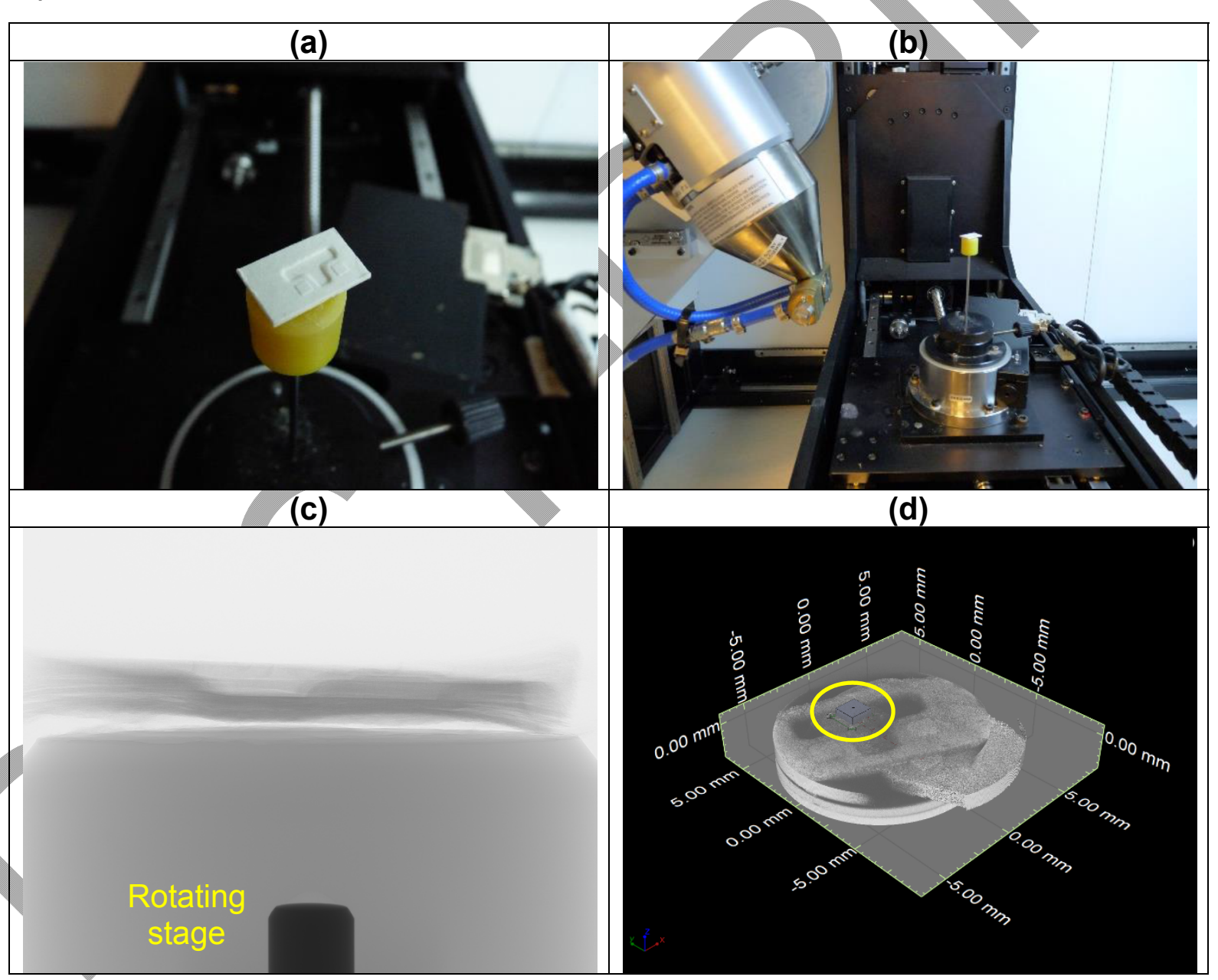

Figure 7: (a) Sample adjustment on the rotating stage of the Nikon XT H 225 industrial CT. (b) Stage placement with respect to the molybdenum target. (c) 2D X-ray radiograph of the sample. (d) Reconstruction of the projections into a 3D volume finalized using the software Nikon Metrology CT PRO 3D version 3.1.9. Circled in yellow is the volume of interest of the void analysis. 
Table 6: Scanning parameters used in this work.

\begin{tabular}{|c|c|c|}
\hline Parameter & Unit & Value \\
\hline Voltage & $\mathrm{V}$ & 178 \\
\hline Current & $\mathrm{A}$ & 2 \\
\hline Target type & - & Molybdenum \\
\hline Voxel size, along all three axes, & $\mu \mathrm{m}$ & 6.6 \\
\hline Number of projections per rotation & - & 2500 \\
\hline Detector pixels & - & $2000 \times 2000$ \\
\hline
\end{tabular}

Radiographs of the X-ray beam passing through the sample were recorded for different angular positions (2500) between $0^{\circ}$ and $360^{\circ}$ (Figure 7 (c)). The reconstruction of the projections into a 3D volume was finalized using the software Nikon Metrology CT PRO 3D version 3.1.9 (Nikon, Tokyo, Japan).

The obtained 3D reconstruction of a sample is depicted in Figure 7 (d). Circled in yellow is the region of interest (ROI) that was extracted in each sample for the subsequent void analysis.

In order to analyze the same volume for each sample and for being consistent in the comparison of the results, the voids analysis was performed on a specifically defined region of interest. A volume of $1.5 \times 1.5 \times 1.0 \mathrm{~mm}$ positioned in the center of the 3D reconstruction was extracted from each sample (yellow circle in Figure 7 (d)).

The void (porosity) analysis was performed using the defect detection tool offered by the software VG studio Max 3.0 (Volume Graphics, Heidelberg, Germany). The tool provided detailed information on each individual void (pore) as well as their global distribution. Figure 8 shows the spatial porosity distribution for the four samples, seen from an internal top view and from a $3 \mathrm{D}$ view. It can be readily observed that the amount of voids increases from sample $1\left(120^{\circ} \mathrm{C}, 8 \mathrm{~s}\right)$ to sample $4\left(160^{\circ} \mathrm{C}, 18 \mathrm{~s}\right)$.

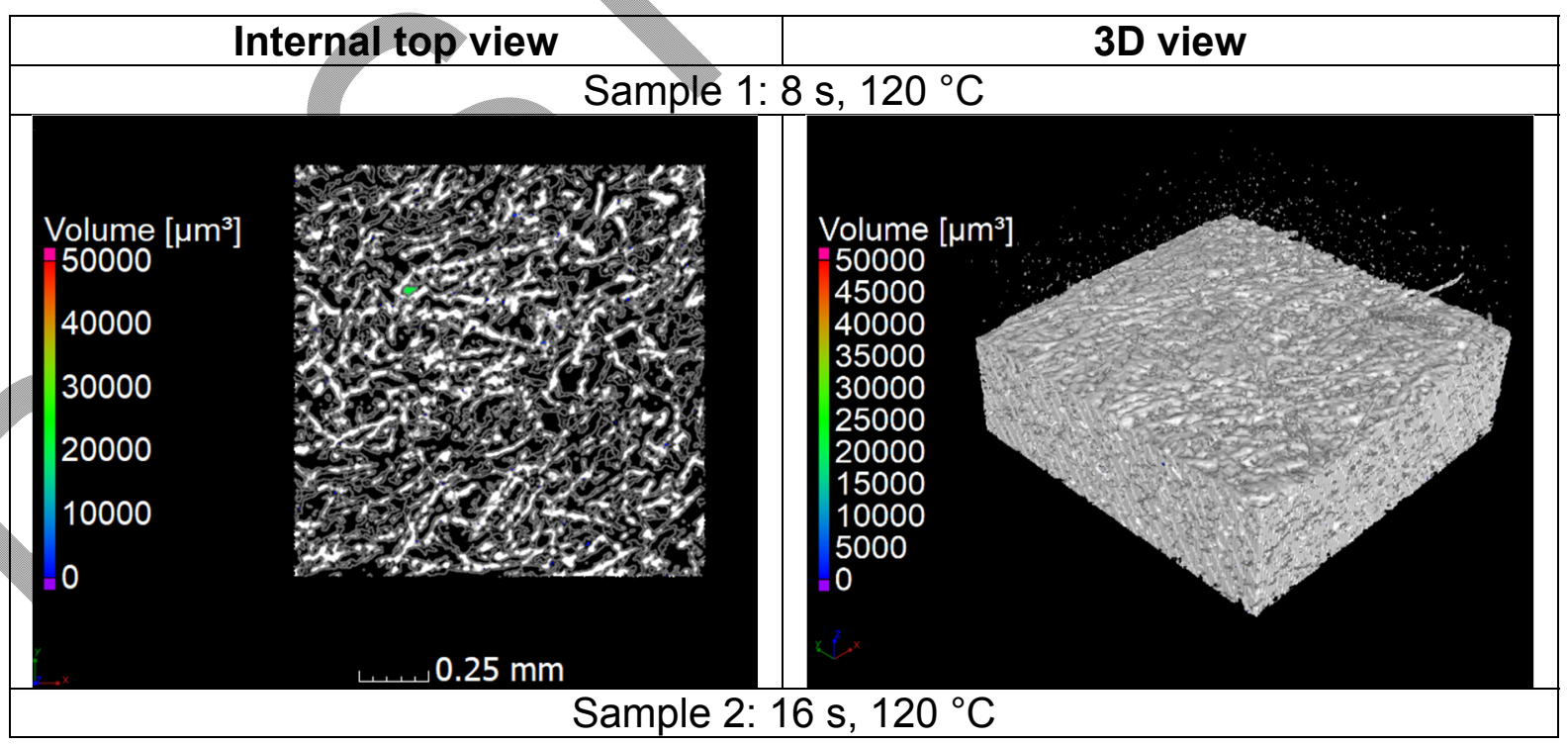




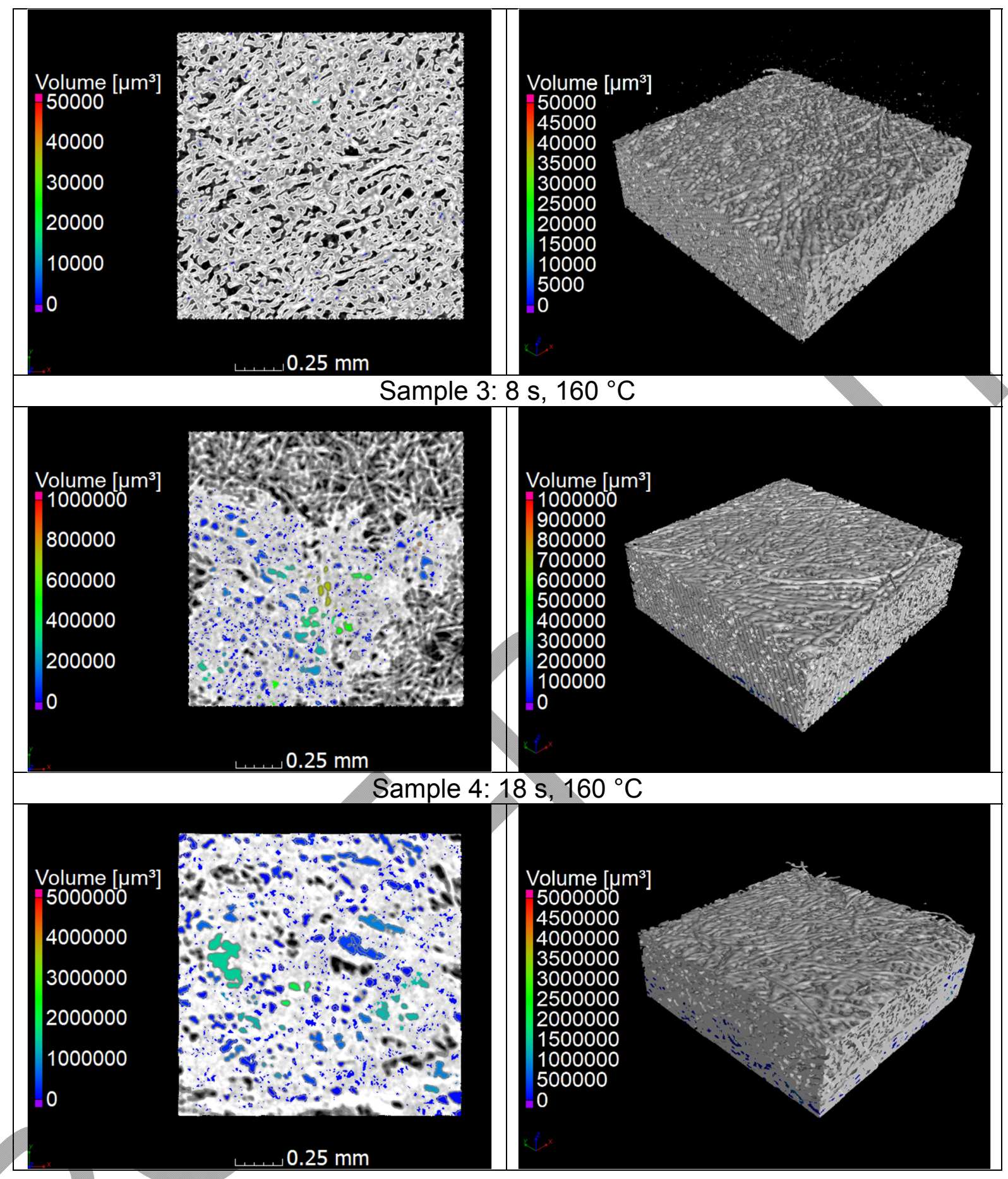

Figure 8: Volume pore distribution for the four molded pulp samples. Volume sizes of volume of $1.5 \times 1.5$ $x 1.0 \mathrm{~mm}$.

\section{Results}

\section{Effect of the process parameters on the dewatering efficiency}

The statistical analysis for the dewatering efficiency, namely dryness, is represented in Figure 9, in the form of a Pareto chart and a main effect plot. The Pareto chart shows the effects of the process parameters under investigation in a descending order, according to their magnitude. In this way, the significance of each factor with respect 
to the efficiency of dewatering during a thermoforming process is clearly identified. An increase of the mold temperature produced an average increase in the items' dryness from $55 \%$ to $80 \%$. The increase of the duration of the vacuum suction led also to an average increase in dryness of around $15 \%$. An increase in the structural pressure and in the contact time were statistically not significant. This evidence is in accordance with the assumption given in ${ }^{37}$, i.e. the energy transfer is independent of the pressure if the applied pressure is above $3 \mathrm{MPa}$.

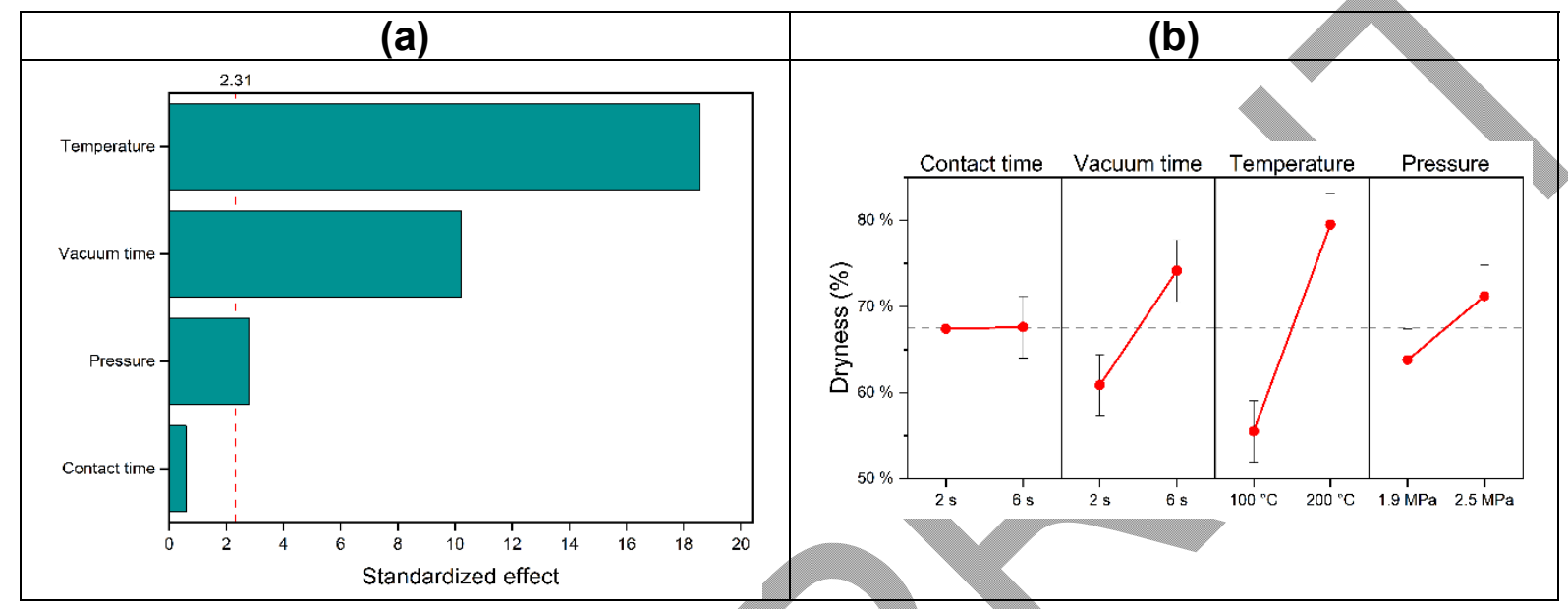

Figure 9: Pareto chart (a) and main effect plot (b) for the dewatering efficiency statistical analysis. The error bars indicate the experimental standard deviation (SD).

Based on these results, the cycle time was referred solely to the duration of the suction via vacuum, active throughout the entire thermoforming process. The effect of the mold's temperature and of the cycle time on the dewatering efficiency was furtherly investigated. The structural pressure was kept fixed at 2.5 MPa. A graph showing the dryness level as a function of mold's temperature and cycle time was created (Figure 10). It was observed the recurrence of manufacturing defects such as blisters and internal delamination for a specific setup of process parameters, marked in red in Figure 10. The formation of the defects was likely occurring when the structural pressure was released, as reported in $8,13,38,39$. Moreover, it is possible to observe that the dryness level present an increasing trend with increasing temperature. In fact, the curve at $100{ }^{\circ} \mathrm{C}$ appears to plateau around a dryness level of $60 \%$, while the curve at $140{ }^{\circ} \mathrm{C}$ presents an increasing trend for the same cycle times. 


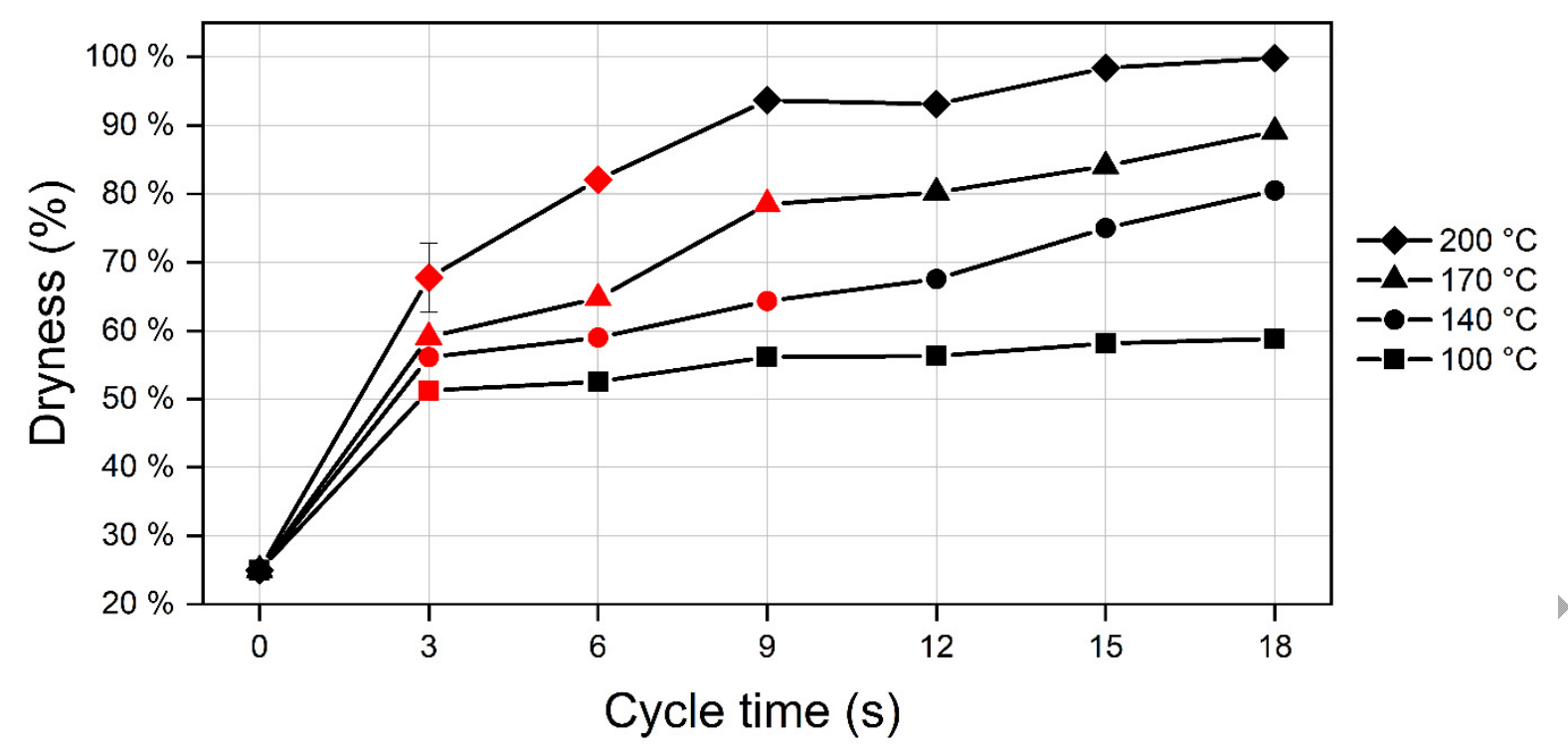

Figure 10: Dryness level as a function of cycle time at four different temperature levels. In red the samples that resulted defective. Data points represent the average of two experiments, and the error bar shows the estimated uncertainty in the data at all points.

\section{Replication quality of micro-features}

Figure 11 to Figure 14 depict the acquisitions of the four geometrical features Step height 1, Step height 2, Width 1 and Width 2 respectively. 20 molded pulp samples were produced with four different DOE setups, each containing four geometrical features, leading to 80 measurement acquisitions. From the images, it is possible to appreciate the roundish shape of the replicated features.

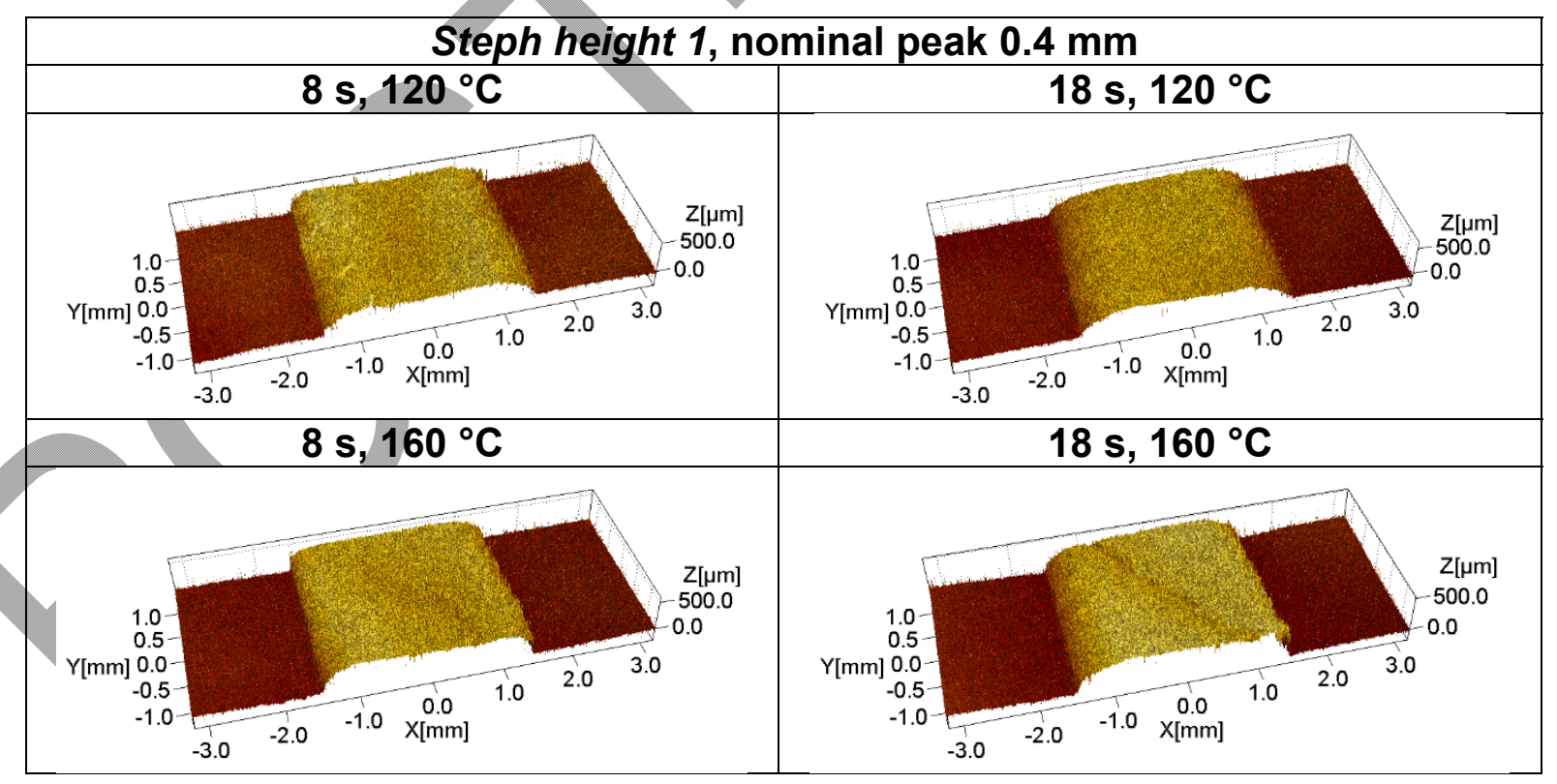

Figure 11: "Step height 1 " acquisitions for the four DOE setups.

\section{Steph height 2, nominal peak $1.5 \mathrm{~mm}$}

$8 \mathrm{~s}, 120^{\circ} \mathrm{C}$

$18 \mathrm{~s}, 120^{\circ} \mathrm{C}$ 


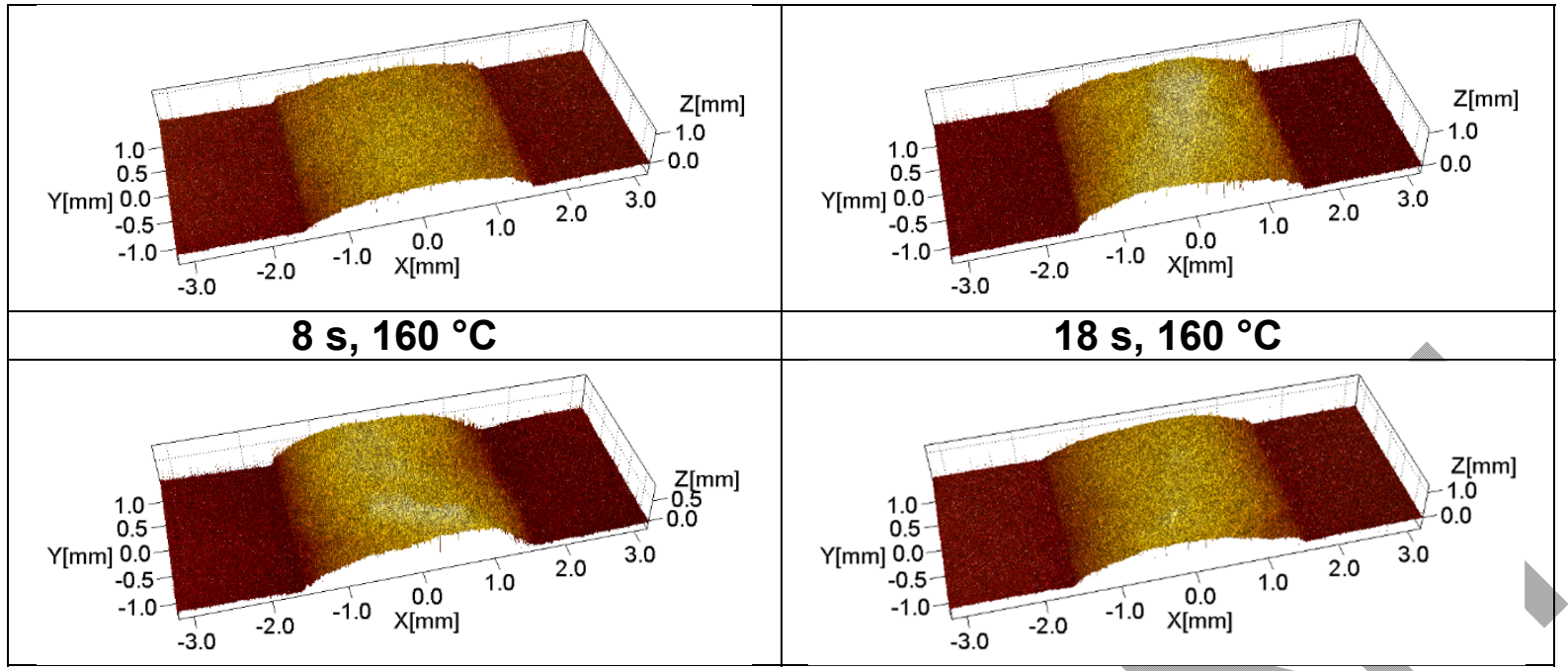

Figure 12: "Step height 2" acquisitions for the four DOE setups.

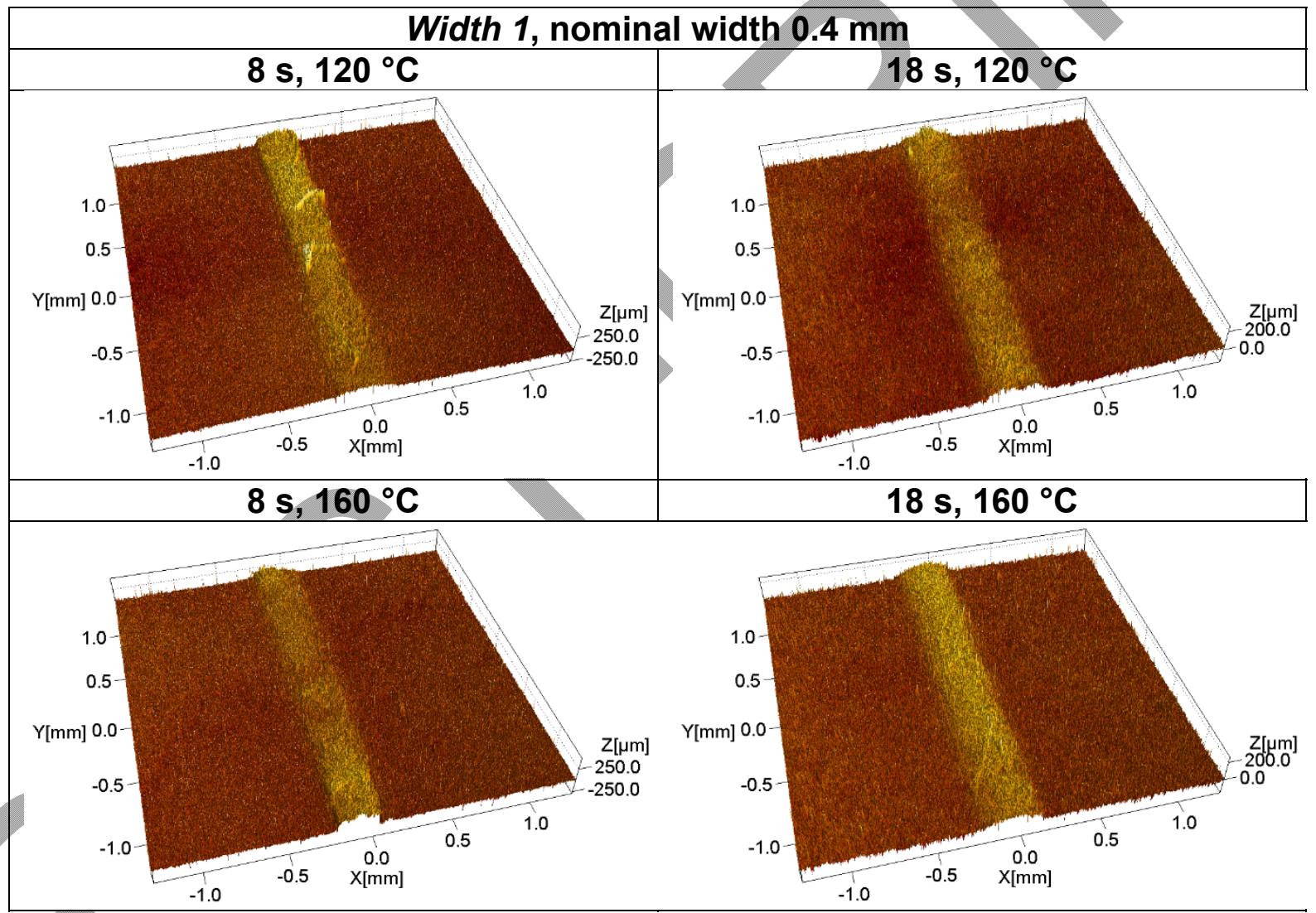

Figure 13: "Width 1" acquisitions for the four DOE setups.

\section{Width 2, nominal width $1.5 \mathrm{~mm}$}

$8 \mathrm{~s}, 120^{\circ} \mathrm{C}$

$18 \mathrm{~s}, 120^{\circ} \mathrm{C}$ 


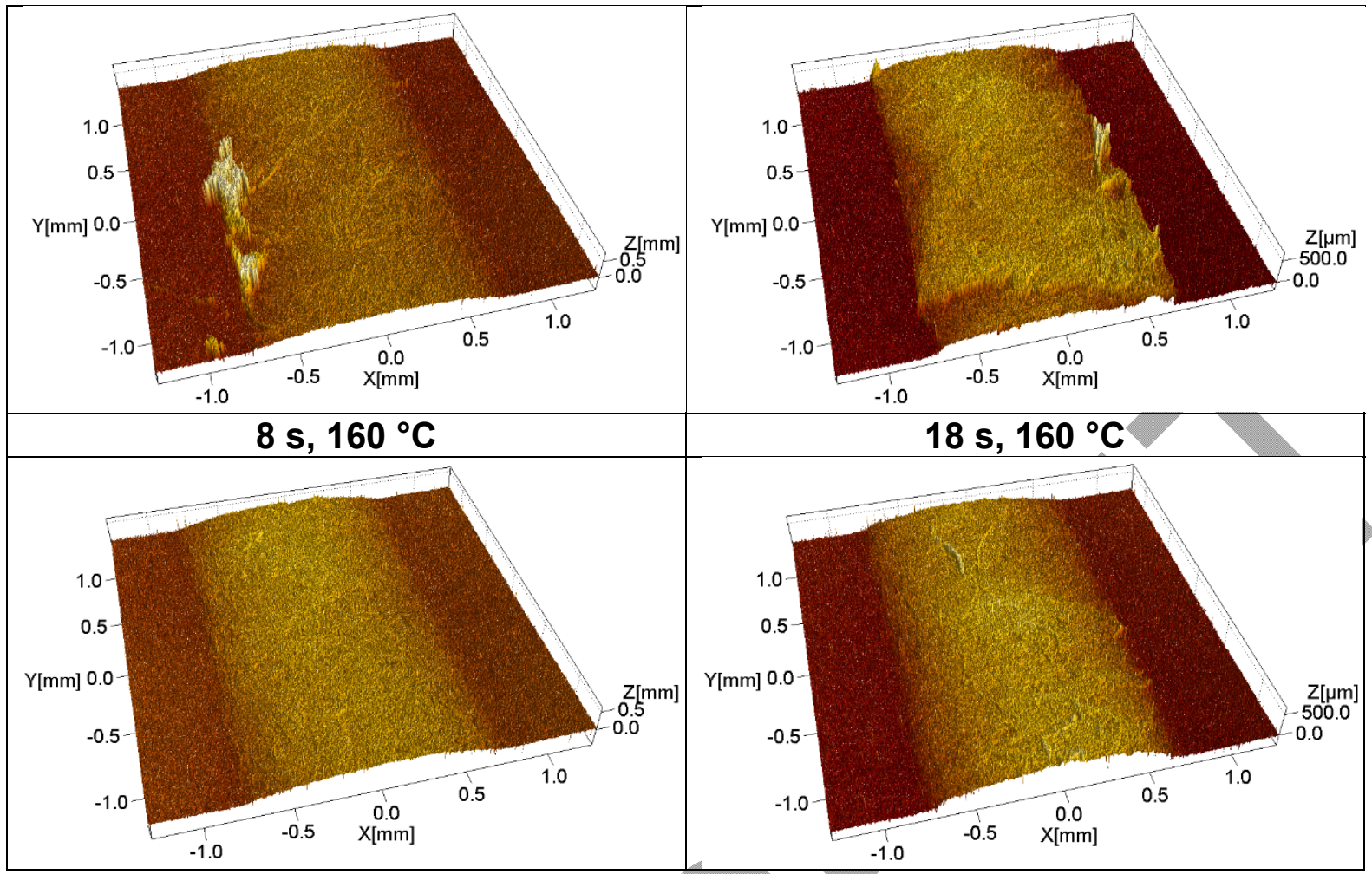

Figure 14: "Width 2" acquisitions for the four DOE setups.

The magnitude of the quality indicator named deviation for the four geometrical features is reported in Figure 15. A higher quality of the replication is achieved when the indicator is close to zero, meaning that the replicated features closely resemble the mold's geometry. It stands out that the worst replicated feature was Step height 2, which corresponded to a nominal peak of $1.5 \mathrm{~mm}$, with a deviation of $60 \%$. The feature Width 2 (nominal width $1.5 \mathrm{~mm}$ ) was also poorly replicated, with a level of deviation around $20 \%$. It was not possible to identify a clear relation between the process parameters setups and the level of deviation.

Features with a greater depth and width were hardly replicated. It is speculate that this limitation is due to the typical large aspect ratio of fibers. The fibers are not compliant to fill a deep cavity, while they more easily adapt to wider cavities. The roundish morphology of the replicated features would indicate that the fibers are subjected to restrained forces from the entangled fibers in the vicinity. It is important to remark that these results relate to the specific pulp type employed in this work, i.e. commercially available bleached chemical pulp. It is also expected that the use of a highly refined pulp would produce a higher degree of replication quality.

The main effect plot reported in Figure 16 represents statistically the influence of four selected factors on the replication quality. These four factors are: features' size, features' type (i.e. Step height or Width), mold's temperature and cycle time. As just discussed, the features of the Width type were better replicated than the Step height type, with an average deviation of $10 \%$. Moreover, features with smaller dimensions were more easily replicated, with an average deviation of $5 \%$. The process parameters, mold's temperature and cycle time, had no statistical significance on the replication process. This would reaffirm that the replication of micro-features on the molded pulp surface is mainly influenced by the nature of the employed fibers. 


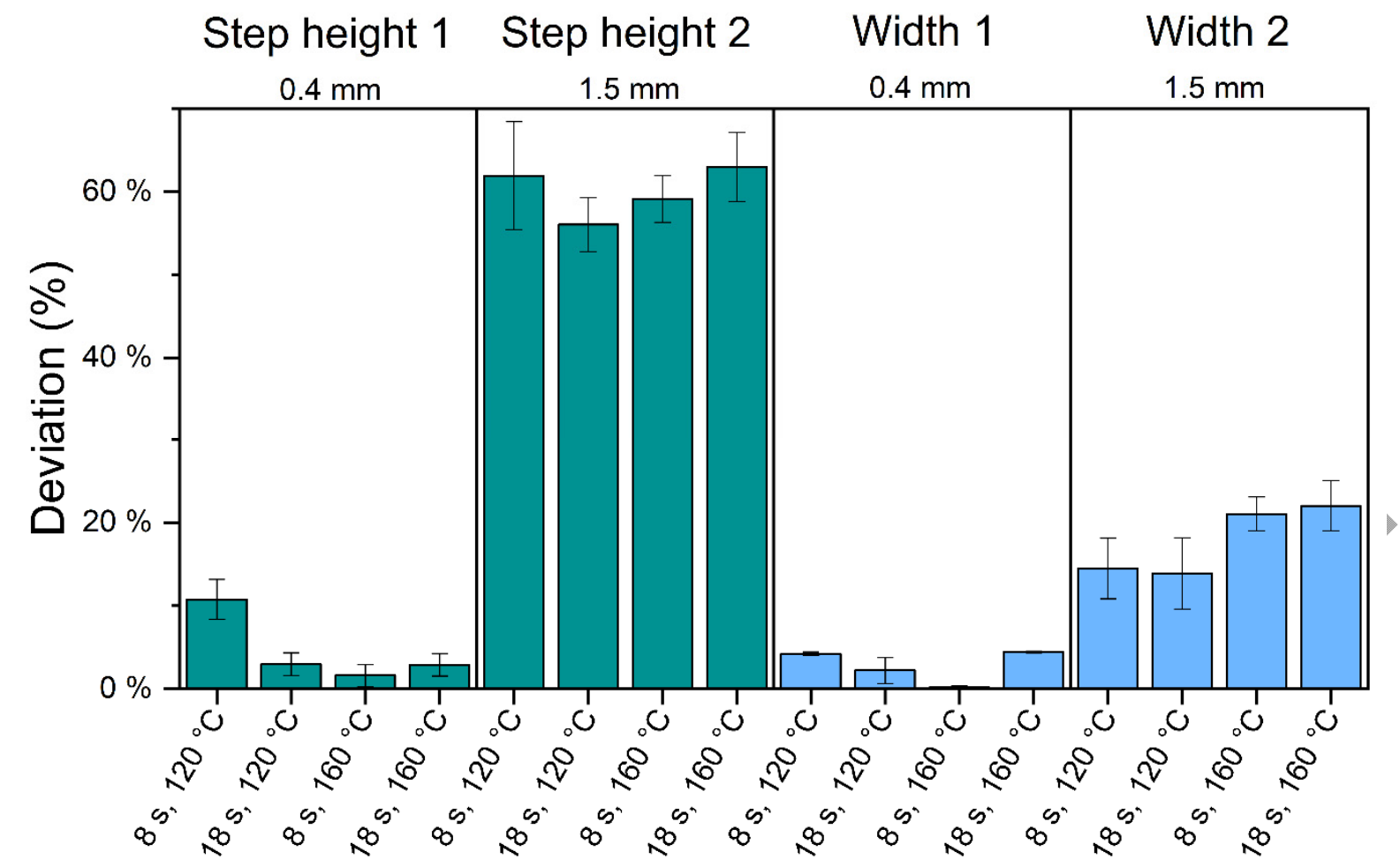

Figure 15: Deviation level of the four replicated geometric features with four different process parameters setups: Set1 $8 \mathrm{~s} 120^{\circ} \mathrm{C}$; Set2 $18 \mathrm{~s} 120^{\circ} \mathrm{C}$; Set3 $8 \mathrm{~s} 160^{\circ} \mathrm{C}$; Set4 $18 \mathrm{~s} 160^{\circ} \mathrm{C}$. Data points represent the average of five measurements, and the error bars on the histograms indicate the experimental standard deviation (SD).

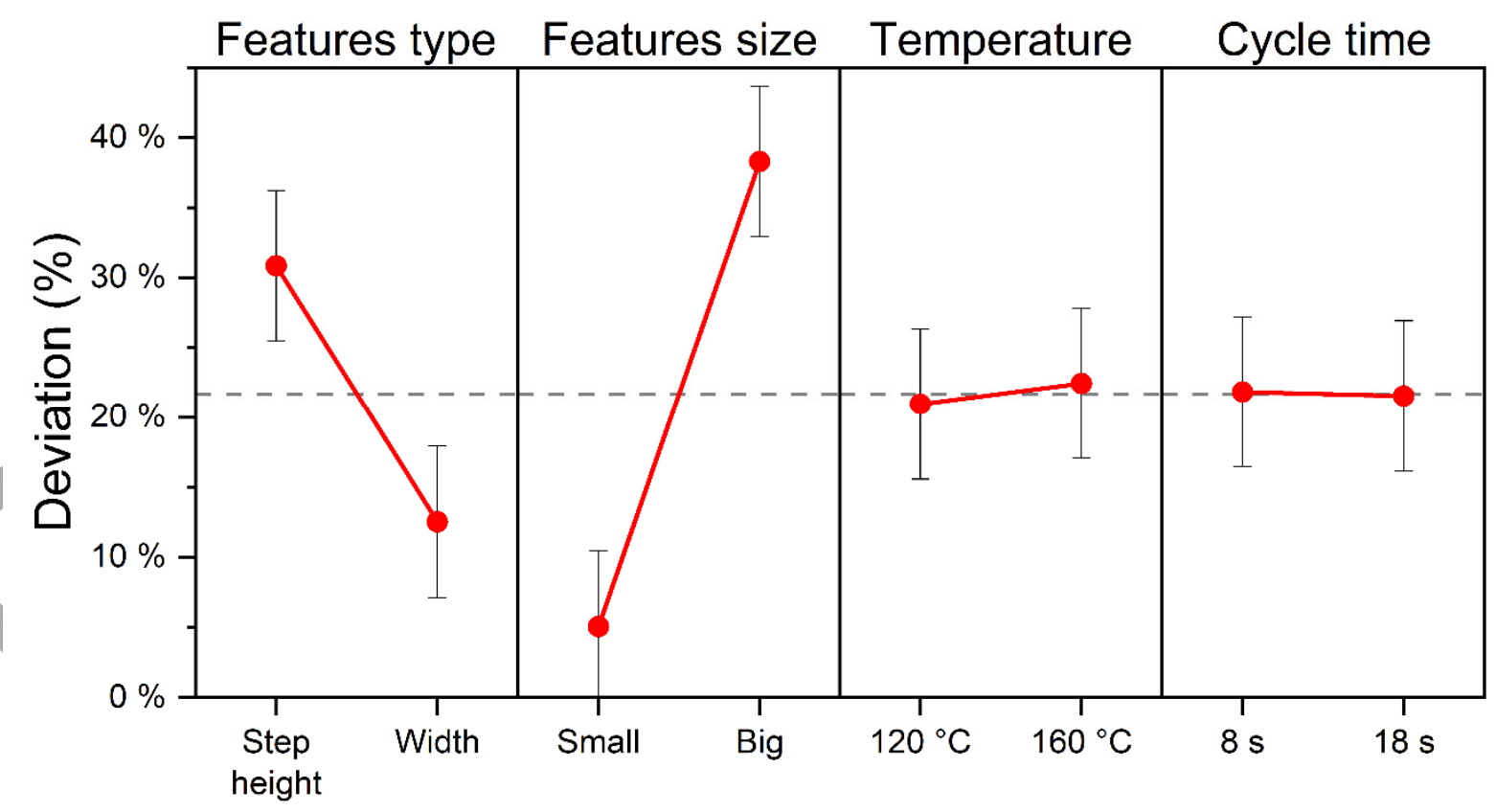

Figure 16: Main effect plot for deviation with respect to features' type and size, mold's temperature and cycle time. The error bars indicate the experimental standard deviation (SD). 


\section{Void analysis with computed tomography}

In Table 7 the results obtained from the void analysis are reported. The minimum void radius captured by the software was $10 \mu \mathrm{m}$, due to the radiographs resolution used during the acquisition. For the ease of the reader, the percentage of voids and the average void radius in each sample are plotted in Figure 17.

Table 7: Results of the void analysis for the selected four molded pulp samples.

\begin{tabular}{|c|c|c|c|c|c|}
\hline $\begin{array}{c}\text { Sample } \\
\text { number }\end{array}$ & $\begin{array}{c}\text { Process } \\
\text { parameters }\end{array}$ & $\begin{array}{c}\text { Voids, } \\
\%\end{array}$ & $\begin{array}{c}\text { Max void } \\
\text { radius, } \boldsymbol{\mu m}\end{array}$ & $\begin{array}{c}\text { Min void } \\
\text { radius, } \boldsymbol{\mu m}\end{array}$ & $\begin{array}{c}\text { Average void } \\
\text { radius, } \boldsymbol{\mu m}\end{array}$ \\
\hline 1 & $8 \mathrm{~s}, 120^{\circ} \mathrm{C}$ & 0.79 & 60 & 10 & 11 \\
\hline 2 & $18 \mathrm{~s}, 120^{\circ} \mathrm{C}$ & 1.67 & 70 & 10 & 15 \\
\hline 3 & $8 \mathrm{~s}, 160^{\circ} \mathrm{C}$ & 10.68 & 530 & 10 & 26 \\
\hline 4 & $18 \mathrm{~s}, 160^{\circ} \mathrm{C}$ & 13.02 & 810 & 10 & 25 \\
\hline
\end{tabular}
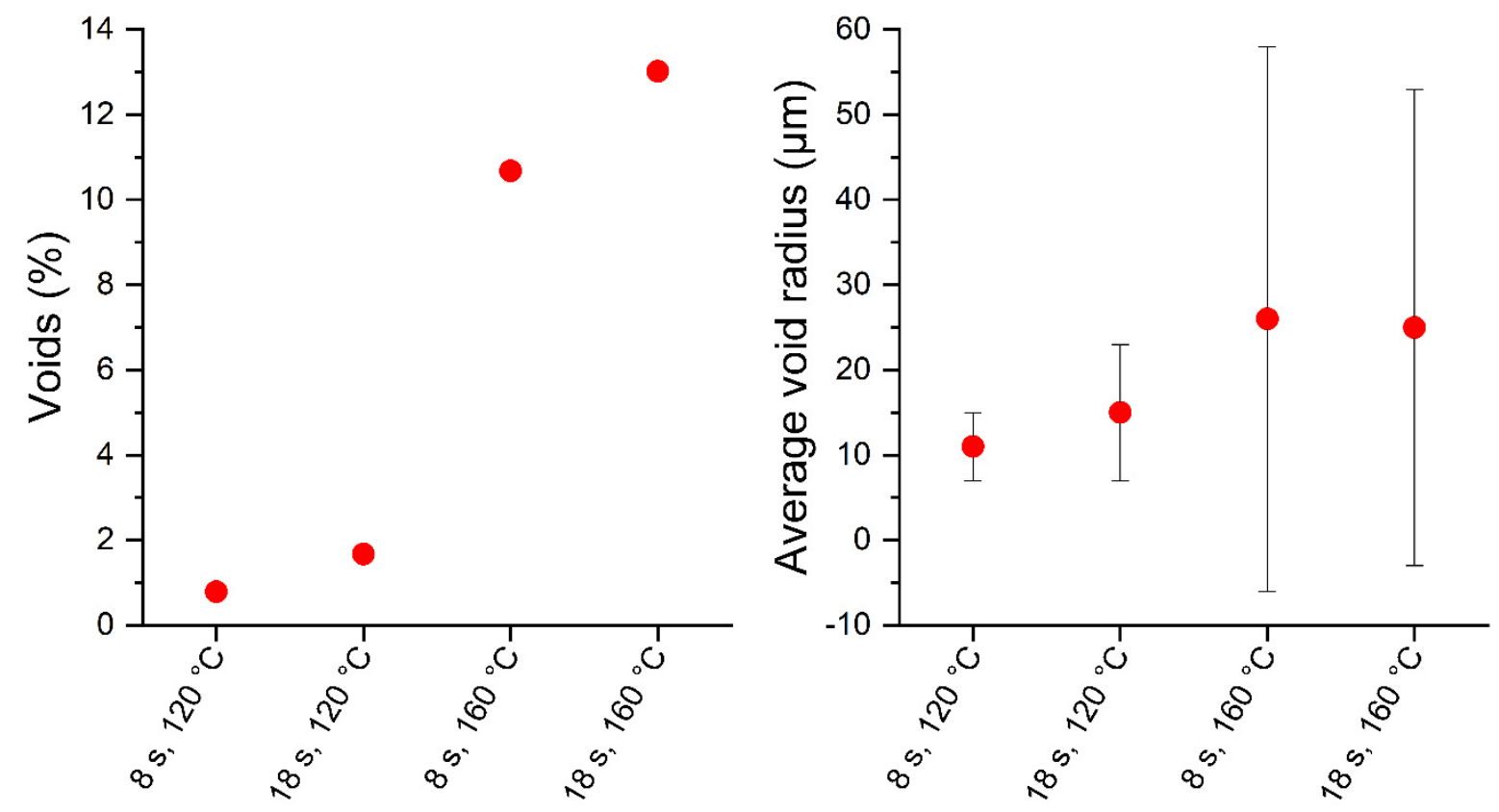

Figure 17: Percentage of voids and average void radius for the void analysis performed with computed tomography.

Based on the obtained results, it is clear that the process parameters have a strong influence on the microstructure of the thermoformed molded pulp samples. As the temperature increases (sample 3 and sample 4), the percentage of voids with respect to the volume analyzed increases up to ten times. A longer cycle time also seems to increase slightly the percentage of pores (sample 2 with respect to sample 1, sample 4 with respect to sample 3 ).

The size of the voids appears to be related to the amount of voids in the volume analyzed. The increase of the temperature during the fabrication of the molded pulp samples caused an increased in the number of voids and their dimensions. The size of the voids had also a larger variation, reveling an inhomogeneity of the molded pulp microstructure. It can be speculated that the increase in temperature (from $120^{\circ} \mathrm{C}$ to $160^{\circ} \mathrm{C}$ ) caused a change of phase of a portion of the water inside the samples during the thermoforming process. The water change of phase into steam is linked with a 
volume increase in the order of 20 times. The steam expansion could be an explanation for the increase of the voids within the molded pulp samples.

\section{Discussion}

In the dewatering efficiency investigation, a marked increase in the dryness level was observed for temperatures above $100{ }^{\circ} \mathrm{C}$. In spite of the applied mechanical load, some areas of the sample might experience a lower thermodynamic pressure (i.e. the portion of the disk that is in the vicinity of the vacuum suction), thus allowing part of the water to turn into steam during the thermoforming process. This would explain the increasing trend in dryness, but a deeper investigation on the pressure distribution is necessary before confirming this hypothesis. Other aspects relating to the use of high temperatures might play a role, such as the thermal softening of the fiber network and a reduction of the water viscosity 40 .

An indication on the presence of steam during the manufacturing of the molded pulp samples resulted also from the void analysis, where an increased number of voids was related to an increase in temperature.

A secondary effect of the water phase change is the occurrence of delamination and related defects, as shown in Figure 10. As it was already reported in the literature (e.g. in ${ }^{39,41}$ ), the defects are related to the dryness level for a specific temperature. In other words, if a large quantity of water is left within the product at a relatively high temperature, the drag forces resulting from the expanding vapor would overcome the cohesive forces that hold the product together, with consequent delamination ${ }^{13}$. Given the control over the process parameters that a thermoforming machine offers, a simple strategy to avoid the appearance of manufacturing defects would be removing the majority of the water content while the structural pressure is still applied. For instance, in this specific set of experiments, by employing a mold temperature of $200{ }^{\circ} \mathrm{C}$, it was necessary to reach a dryness level above $90 \%$ to avoid the delamination of the molded pulp item.

The statistical analysis for the dewatering efficiency also showed that an increase in temperature appears to be beneficial. Nevertheless, an extremely high temperature might cause hornification of the paper layer in direct contact with the mold's heated surface ${ }^{42,43}$. This phenomenon could prevent an efficient heat diffusion within the molded product and a consequent reduction of the dewatering efficiency.

The mechanism of water removal during the thermoforming of molded pulp is similar in nature to impulse drying. As in the impulse technology, the water phase change appears to have an effect on the physics of dewatering. The conduction of heat certainly plays an important role, and a simple model of the heat transport in a wet capillary-porous materials is provided in this article. Yet, a rigorous description of the process would require a modelling effort, which could be inspired to the available literature around impulse drying and hot pressing. 


\section{Conclusions}

Molded pulp products are an emerging eco-friendly packaging solution. The category manufactured with thermoforming produces high quality, thin-walled items. The purpose of this study was to characterize the thermoforming process of molded pulp products and their characteristics. The effect of the process parameters on multiple quality criteria was investigated. The quality criteria considered were the dewatering efficiency of the process, the capability of molding features at the micro-scale on the items' surface and the voids distribution within the internal microstructure. In particular, this work comprises of three investigations. The first one aims at characterizing the process while the other two focus on the geometrical accuracy and internal structure of the parts.

Experimental results and statistical analysis showed that:

- Among the four process parameters considered in this research (contact time, vacuum time, temperature and pressure), results showed that the mold's temperature and the duration of the suction via vacuum were the most effective in increasing the dewatering level of the molded pulp parts. The duration of the contact time had instead no impact.

- The observed manufacturing defects, namely delamination and surface blistering, can be avoid by achieving a specific dryness level for a certain process setup. By reducing the water content left within the sample prior to the release of the structural pressure, the occurrence of manufacturing defects can be reduced. This strategy is readily available given the control over the process parameters that a thermoforming machine offers

- The geometrical accuracy with which features in the micro-range are molded on the molded pulp items' surface was assessed. The replicating process was limited by the nature of the fibers, which were not compliant in filling the deeper cavities.

- The internal microstructure of the molded pulp products analyzed in this work was strongly influenced by the mold's temperature. The voids fraction increased up to ten times with increasing temperature from $120^{\circ} \mathrm{C}$ to $160{ }^{\circ} \mathrm{C}$. It is speculated that the change in temperature promotes a larger portion of water to change phase into steam, thus creating a larger void fraction within the part.

The void analysis and the increase trend of the dryness level with increasing temperature would suggest that the water phase change plays a role in the mechanism of water removal. Further research could be inspired by the literature around two technologies that are similar in nature to thermoforming, namely impulse drying and hot pressing.

In conclusion, in order to produce high quality parts with a high dewatering efficiency, correct adjustment of the process parameters is crucial. In particular, the mold's temperature and the duration of the vacuum suction proved to have the greater importance. The geometrical accuracy of the parts is instead more dependently related to the pulp type employed. 


\section{Acknowledgements}

The authors gratefully acknowledge the Innovations Fund Denmark for grant no. 510600006B furnished for the project titled "Impulse Drying of cardboard moulded 3D structures". The grant made possible to fund a consortium between the Department of Mechanical Engineering of the Technical University of Denmark, EcoXpac A/S and the Carlsberg Group. Special thanks go to the Imaging Industry Centre of the Technical University of Denmark for making the CT scanner available.

\section{Literature}

1. Didone M, Saxena P, Brilhuis-Meijer E, et al. Moulded Pulp Manufacturing: Overview and Prospects for the Process Technology. Packag Technol Sci. 2017;30(6). doi:10.1002/pts.2289

2. Moulded pulp products - overview and developments. Pap Technol. 2011;52(3):28-29.

3. Ljubomir S. L, Milorad V. K, Ilija M. J. Pulp moulding machines for the production of packing paper elements. Hem Ind 2005. http://findit.dtu.dk/en/catalog/2377971050. Accessed June 21, 2018.

4. Huang Li-fei;, He Ke-zhi; Wang Da-wei. Research on the processing technique, common problems and measures of molded pulp products. Packag Food Mach. 2009;27(3). http://findit.dtu.dk/en/catalog/2299323367. Accessed June 21, 2018.

5. Wahren D. Impulse Drying. In: The 47th Executives' Conference. ; 1983:54-60.

6. Orloff DI. Impulse drying of paper: a review of recent research. In: Proceedings from the 14th National Industrial Energy Technology Conference, Houston, TX. ; 1992:110-116.

7. Mendes P, Belgacem N, Bloch JF. Impulse drying technology: The state of the art and the recent advances. Atip Assoc Tech L'industrie Papet. 2004;58(1):2534.

8. Orloff DI. Impulse drying of linerboard: Control of delamination. Annu Meet Tech Sect Can Pulp Pap Assoc Prepr. 1991;(pt B):9-25.

9. Zavaglia JC, Lindsay JD. Flash X-ray visualization of multiphase flow during impulse drying. Tappi J. 1989:79-85.

10. Macklem EA. Impulse drying - a pressing/flashing drying phenomena. In: Engineering Conference, Proceedings of the Technical Association of the Pulp and Paper Industry. ; 1988.

11. Lucisano MFC, Martin AR. Visualization of liquid-vapor phase change phenomena in impulse technology. Tappi J. 2006;5(6):15-21.

12. Orloff DI, Patterson TF, Parviainen PM. Opening the operating window of impulse drying-Part II: Pressure differential as a source of delamination. In: Tappi Engineering \& Papermakers Conference. Vol 81. ; 1997:195-203. 
13. Lucisano MFC, Mazzatorta P, Martinez DM. On the mechanism of steam forming during impulse pressing of wet paper webs. Nord Pulp Pap Res J. 2001;16(4):355-361.

14. Hansen HN, Hocken RJ, Tosello G. Replication of micro and nano surface geometries. CIRP Ann. 2011;60(2):695-714. doi:10.1016/j.cirp.2011.05.008

15. Hansen HN. Dimensional micro and nano metrology. In: CIRP Kolloquium Switzerland. ; 2006.

16. Hocken RJ, Chakraborty N, Brown C. Optical Metrology of Surfaces. CIRP Ann. 2005;54(2):169-183. doi:10.1016/S0007-8506(07)60025-0

17. Baruffi F, Parenti P, Cacciatore F, Annoni M, Tosello G. On the application of replica molding technology for the indirect measurement of surface and geometry of micromilled components. Micromachines. 2017;8(6). doi:10.3390/mi8060195

18. Lavrykov S, Singh SK, Ramarao B V., Ramaswamy S, Pande H. Analysis of the permeability tensor and the correlation length of heterogeneities in paper using X-ray microtomography. Dry Technol. 2016;34(8):871-882. doi:10.1080/07373937.2015.1057837

19. Ramarao B V., Massoquete A, Lavrykov S, Ramaswamy S. Moisture Diffusion Inside Paper Materials in the Hygroscopic Range and Characteristics of Diffusivity Parameters. Dry Technol. 2003;21(10):2007-2056. doi:10.1081/DRT120027044

20. du Roscoat SR, Bloch J-F, Caulet P. A method to quantify the 3D microstructure of fibrous materials containing mineral fillers using X-ray microtomography: application to paper materials. J Mater Sci. 2012;47(18):6517-6521. doi:10.1007/s10853-012-6575-z

21. Marulier, C.; Dumont, P. J. J.; Orgeas, L.; Caillerie, D.; du Roscoat SR. Towards 3D analysis of pulp fibre networks at the fibre and bond levels. Nord Pulp Pap Res J. 2012;27(02):245-255. doi:10.3183/NPPRJ-2012-27-02-p245-255

22. Roscoat SR du, Bloch J-F, Thibault X. Synchrotron radiation microtomography applied to investigation of paper. J Phys D Appl Phys. 2005;38(10A):A78-A84. doi:10.1088/0022-3727/38/10A/015

23. Viguié J, Dumont PJJ, Mauret É, et al. Analysis of the hygroexpansion of a lignocellulosic fibrous material by digital correlation of images obtained by X-ray synchrotron microtomography: application to a folding box board. J Mater Sci. 2011;46(14):4756-4769. doi:10.1007/s10853-011-5386-y

24. Marulier C, Dumont PJJ, Orgéas L, Rolland du Roscoat S, Caillerie D. 3D analysis of paper microstructures at the scale of fibres and bonds. Cellulose. 2015;22(3):1517-1539. doi:10.1007/s10570-015-0610-6

25. Axelsson M, Svensson S. 3D pore structure characterisation of paper. Pattern Anal Appl. 2010;13(2):159-172. doi:10.1007/s10044-009-0146-1

26. Wernersson, E. L. G.; Borodulina, S.; Kulachenko, A; Borgefors G. Characterisations of fibre networks in paper using micro computed tomography images. Nord Pulp Pap Res J. 2014;29(3). 
27. Sharma $Y$, Phillion $A B$, Martinez DM. Automated segmentation of wood fibres in micro-CT images of paper. J Microsc. 2015;260(3):400-410. doi:10.1111/jmi.12308

28. Miettinen A, Chinga-Carrasco G, Kataja M. Three-Dimensional Microstructural Properties of Nanofibrillated Cellulose Films. Int J Mol Sci. 2014;15(4):64236440. doi:10.3390/ijms15046423

29. Tappi. Forming handsheets for physical tests of pulp - T205. 1995:1-9.

30. Palosaari SM, Cornish ARH. Approximate method for the prediction of the effective thermal conductivity of wetter porous materials. Acta Polytech Scand Chem Incl Met Ser Ch. 1976.

31. Karlsson M., Stenström S. Static and Dynamic Modeling of Cardboard Drying Part 1: Theoretical Model. Dry Technol. 2005;23(1-2):143-163. doi:10.1081/DRT-200047954

32. SPIPTM - Scanning Probe Image Processor Software / Image Metrology. https://www.imagemet.com/products/spip/. Accessed March 16, 2018.

33. De Chiffre L, Carmignato S, Kruth J-P, Schmitt R, Weckenmann A. Industrial applications of computed tomography. CIRP Ann. 2014;63(2):655-677. doi:10.1016/j.cirp.2014.05.011

34. Kruth JP, Bartscher M, Carmignato S, Schmitt R, De Chiffre L, Weckenmann A. Computed tomography for dimensional metrology. CIRP Ann. 2011;60(2):821842. doi:10.1016/j.cirp.2011.05.006

35. Bensadoun F, Barburski M, Straumit I, et al. Challenges of X-Ray Tomography Technique on Natural Fibre-Based Composites. In: 11th European Conference on Non-Destructive Testing (ECNDT 2014). ; 2014.

36. X-ray Transition Energies Search Form. https://physics.nist.gov/PhysRefData/XrayTrans/Html/search.html. Accessed April 4, 2018.

37. Nilsson J, Stenström S, Modelling of Heat Transfer in Hot Pressing and Impulse Drying of Paper. Dry Technol. 2001;19(10):2469-2485. doi:10.1081/DRT100108249

38. Orloff DI, Patterson T, Krause AM. Opening the operating window of impulse drying-Part 1. The effect of ambient pressure at nip opening. In: Tappi Engineering \& Papermakers Conference. ; 1997.

39. Lucisano MFC. On heat and paper: from hot pressing to impulse technology. 2002.

40. Bloch J-F., Auriault J-L. Heat transfer in nonsaturated porous media: Modelling by homogenisation. Transp Porous Media. 1998;30(3):301-321. doi:10.1023/A:1006540912415

41. Orloff DI. Impulse drying of linerboard: control of delamination. In: CPPA 77th Annual Meeting. ; 1991.

42. Fernandes Diniz JMB, Gil MH, Castro JAAM. Hornification - Its origin and 


$$
\mathrm{P}^{S^{2}}
$$

